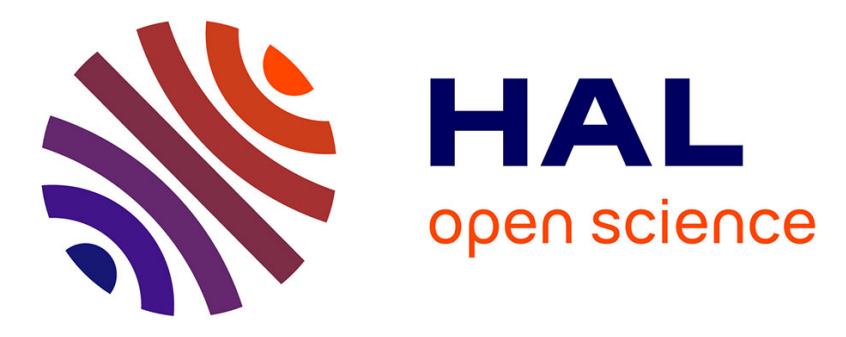

\title{
Widespread Exposures of Extensive Clean Shallow Ice in the Mid-Latitudes of Mars
}

\author{
Colin M Dundas, Michael T Mellon, Susan Conway, Ingrid J Daubar, Kaj E \\ Williams, Lujendra Ojha, James J Wray, Ali M Bramson, Shane Byrne, \\ Alfred S Mcewen, et al.
}

\section{To cite this version:}

Colin M Dundas, Michael T Mellon, Susan Conway, Ingrid J Daubar, Kaj E Williams, et al.. Widespread Exposures of Extensive Clean Shallow Ice in the Mid-Latitudes of Mars. Journal of Geophysical Research. Planets, 2021, 126 (3), pp.e2020JE006617. 10.1029/2020JE006617. hal03186594

\section{HAL Id: hal-03186594 https://hal.science/hal-03186594}

Submitted on 31 Mar 2021

HAL is a multi-disciplinary open access archive for the deposit and dissemination of scientific research documents, whether they are published or not. The documents may come from teaching and research institutions in France or abroad, or from public or private research centers.
L'archive ouverte pluridisciplinaire HAL, est destinée au dépôt et à la diffusion de documents scientifiques de niveau recherche, publiés ou non, émanant des établissements d'enseignement et de recherche français ou étrangers, des laboratoires publics ou privés. 
1 Widespread Exposures of Extensive Clean Shallow Ice in the Mid-Latitudes of Mars

3 Colin M. Dundas ${ }^{\mathrm{a}}$ *

$4 \quad$ Michael T. Mellon ${ }^{\mathrm{b}}$

$5 \quad$ Susan J. Conway ${ }^{\mathrm{c}}$

6 Ingrid J. Daubar ${ }^{\mathrm{d}}$

$7 \quad$ Kaj E. Williams ${ }^{\mathrm{a}}$

8 Lujendra Ojha $a^{\mathrm{e}}$

9 James J. Wray ${ }^{\mathrm{f}}$

10 Ali M. Bramson ${ }^{\mathrm{g}}$

11 Shane Byrne ${ }^{\mathrm{h}}$

12 Alfred S. McEwen ${ }^{\mathrm{h}}$

13 Liliya V. Posiolova ${ }^{\mathrm{i}}$

14 Gunnar Speth ${ }^{\mathrm{i}}$

15 Donna Viola ${ }^{\mathrm{j}}$

16 Margaret E. Landis ${ }^{\mathrm{k}}$

17 Gareth A. Morgan ${ }^{1}$

18 Asmin V. Pathare ${ }^{1}$

19

$20{ }^{a}$ U.S. Geological Survey, Astrogeology Science Center, 2255 N. Gemini Dr., Flagstaff,

21 AZ 86001, USA (cdundas@usgs.gov).

$22{ }^{\mathrm{b}}$ Center for Astrophysics and Planetary Science, Cornell University, Ithaca, NY, USA. 
23 'Laboratoire de Planétologie et Géodynamique CNRS UMR 6112, Université de Nantes,

24 France.

25 dDepartment of Earth, Environmental, and Planetary Sciences, Brown University,

26 Providence, RI, USA.

27 'epepartment of Earth and Planetary Sciences, Rutgers University, Piscataway, NJ, USA.

28 f School of Earth and Atmospheric Sciences, Georgia Institute of Technology, Atlanta,

29 GA, USA.

$30{ }^{\mathrm{g}}$ Department of Earth, Atmospheric, and Planetary Sciences, Purdue University, West

31 Lafayette, IN, USA.

32 hLunar and Planetary Laboratory, The University of Arizona, Tucson, AZ, USA.

33 'Malin Space Science Systems, San Diego, CA, USA.

$34 \quad{ }^{j}$ NASA Ames Research Center, Moffett Field, CA, USA.

$35{ }^{k}$ Laboratory for Atmospheric and Space Physics, University of Colorado, Boulder, CO,

36 USA.

37 'Planetary Science Institute, Tucson, AZ, USA.

38

$39 *$ Corresponding author.

40

41

42

43 


\section{Abstract}

45 Although ice in the Martian mid-latitudes is typically covered by a layer of dust or

46 regolith, it is exposed in some locations by fresh impact craters or in erosional scarps. In

47 both cases, the exposed ice is massive or excess ice with a low lithic content. We find

48 that erosional scarps occur between $50-61^{\circ}$ north and south latitude and that they are

49 concentrated in and near Milankovič crater in the northern hemisphere and southeast of

50 the Hellas basin in the southern hemisphere. These may represent locations of

51 particularly thick or clean bodies of ice. Pits created by retreat of the scarps represent

52 sublimation-thermokarst landforms that evolve in a manner distinct from other ice-loss

53 landforms on Mars. New impact craters reveal that clean subsurface ice is widespread at

54 middle and high latitudes in both hemispheres at depths less than 1 meter. Both the depth

55 to ice and the ice content appear to exhibit significant variability over tens to hundreds of

56 meters. The lowest-latitude exposed ice is near $39^{\circ} \mathrm{N}$ and is at the edge of a region where

57 impact exposures between $40-50^{\circ} \mathrm{N}$ are common, consistent with other indications of a

58 high ice content. This lowest-latitude ice may be currently unstable and subliming.

59 Impact craters on lineated valley fill excavate ice blocks that may represent the top of

60 debris-covered glacial ice. Together, these landforms indicate widespread, clean

61 subsurface ice at middle latitudes on Mars. The distribution and properties of this ice

62 could provide information about past climate conditions.

\section{Plain Language Summary}

65 Ice occurs at the surface near the north and south poles of Mars, but in the mid-

66 latitudes it is usually buried beneath rocks and dust. Impact craters and erosion expose 
67 the ice in some places. At these locations, the ice is generally clean, with little dust or 68 rocky material embedded within it, in contrast with pore ice filling in voids in soil. The 69 erosional exposures are concentrated in and near Milankovič crater in the northern

70 hemisphere and southeast of the Hellas basin in the southern hemisphere and occur at a 71 narrow range of latitudes. These may be locations of particularly thick, clean ice. Impact

72 craters reveal that some amount of such subsurface ice is widespread. The craters help to

73 define the lowest latitude where ice is present and how deeply it is buried, which could

74 provide information about the history of the climate on Mars.

75 


\section{Introduction}

One of the key needs identified by the Mars science community is the inventory

78 and characterization of non-polar near-surface ice (Smith et al., 2018; MEPAG ICE-SAG

79 Report, 2019). This is a fundamental question for determining the near-surface $\mathrm{H}_{2} \mathrm{O}$

80 abundance on Mars and the processes by which it is transported, deposited, and modified.

81 Theory indicates that ice stability is controlled by temperature and the atmospheric water

82 vapor content (e.g., Leighton and Murray, 1966; Mellon and Jakosky, 1993; 1995;

83 Mellon et al., 2004; Schorghofer and Aharonson, 2005; Chamberlain and Boynton, 2007;

84 Steele et al., 2017), and thus a stability boundary varies over time depending on the

85 history of those parameters. This climatic change in turn is governed by variations in

86 Mars' orbit and obliquity (e.g., Murray et al., 1973; Ward, 1973; Laskar et al., 2004).

87 Small adjustments of the ice-table depth in response to climate changes can occur within

88 hundreds of years even in the presence of salt crusts or other plausible diffusion barriers

89 (e.g., Mellon et al., 2004; Hudson and Aharonson, 2008). However, thick bodies of ice

90 might survive through intervals of instability (e.g., Schorghofer and Forget, 2012;

91 Bramson et al., 2017). There is evidence that shallow ( $<10 \mathrm{~m})$ mid-latitude ice has

92 survived for tens of millions of years (Viola et al., 2015) and debris-covered glaciers have

93 an estimated mean age of 110 Ma since the last major ice accumulation (Fassett et al.,

94 2014). Thus the distribution of ice is influenced by its stability in the geologically recent

95 past as well as the present. Additionally, early expectations were that most subsurface ice

96 would simply fill in the pore space of the regolith (e.g., Squyres and Carr, 1986; Mellon

97 and Jakosky, 1993). However, many lines of evidence (e.g., Boynton et al., 2002; Mellon

98 et al., 2009; Smith et al., 2009; Mouginot et al., 2010; Conway and Balme, 2014; 
99 Bramson et al., 2015; Dundas et al., 2015; Stuurman et al., 2016; Pathare et al., 2018)

100 now point to the widespread occurrence of excess or massive ice (terminology per van

101 Everdingen (1998)) rather than pore ice, requiring additional processes such as snowfall

102 (e.g., Madeleine et al., 2009; 2014), thermal cycling to enhance porosity (Fisher, 2005),

103 or migration of thin liquid films to generate ice lenses (e.g., Sizemore et al., 2015).

104 Hence, assessing the distribution, concentration, and structure of ground ice is vital for 105 understanding recent Martian climate and its variations.

106 Ground ice in the Martian mid-latitudes is widespread, but almost always

107 underneath a desiccated protective layer of dry permafrost. This structure was first

108 predicted by Leighton and Murray (1966) and subsequently confirmed by refined models

109 (e.g., Mellon et al., 2004; Schorghofer and Aharonson, 2005; Chamberlain and Boynton,

110 2007; Steele et al., 2017). Observations from gamma-ray and neutron spectroscopy (e.g.,

111 Boynton et al., 2002; Mitrofanov et al., 2018; Pathare et al., 2018), thermal emission

112 (e.g., Bandfield, 2007; Bandfield and Feldman, 2008; Piqueux et al., 2019), and direct

113 excavation by the Phoenix lander (Mellon et al., 2009; Smith et al., 2009) confirm this

114 structure. Unfortunately, the desiccated layer shields the ice from direct view, and

115 exposed ice is expected to sublimate rapidly at mid-latitudes and create a new covering

116 deposit, so the ice is usually concealed beneath dust and regolith.

117 Natural exposures provide local information about the current state of subsurface

118 ice, such as the ice content, geographic distribution, and layering at each site. There are

119 two main categories of natural exposure. Small craters (Fig. 1a) pierce the desiccated

120 cover and create temporary exposures or excavate formerly buried ice onto their ejecta

121 blankets (Byrne et al., 2009; Dundas et al., 2014). These constitute high-resolution point 
122 samples of the ice table and provide a valuable data set for comparison with less-direct,

123 lower-resolution approaches to understanding the distribution of ice. However, these

124 craters are small and shallow features, and the impact events also modify the ice relative

125 to its baseline state. Direct, high-resolution vertical information on undisturbed mid-

126 latitude ice structure was minimal until the discovery of scarp exposures (Fig. 1b) cutting

127 through the ice (Dundas et al., 2018). The scarps are kilometers long, tens of meters high,

128 and expose cross sections through the ice, revealing layering and unconformities. This ice

129 was interpreted as sintered snow with a very low lithic content, and indications of glacial

130 flow exist at one location. Rocks ( $>50 \mathrm{~cm}$ diameter) fell out of one of the scarps over

131 three Mars years, suggesting ongoing sublimation, which was also indicated by

132 weakening of $\mathrm{H}_{2} \mathrm{O}$ spectral absorption features over the course of the summer (Dundas et

133 al., 2018). In addition to the scarps and craters, exposed ice has been reported in some

134 gully alcoves where it may be exposed by active erosion (Dundas et al., 2019; Khuller

135 and Christensen, 2019), but this process has not been studied in depth.

136 The scarps are incised in surface-mantling deposits. Latitude-dependent mantle

137 deposits were first observed by Mariner 9 (Soderblom et al., 1973). They were initially

138 thought to be aeolian dust deposits, but higher-resolution imaging provided evidence that

139 they contain ice (Mustard et al., 2001), in some cases forming thick units with a high ice

140 content (Conway and Balme, 2014). Layering indicates deposition in multiple distinct

141 episodes (Schon et al., 2009). Polygonal cracking visible in some of these units (e.g.,

142 Mangold, 2005; Levy et al., 2009a) indicates a structural integrity that is best interpreted

143 as thermal contraction cracking of solid ice or ice-cemented regolith. These surface-

144 mantling deposits are now widely thought to have been deposited as mixtures of snow or 
145 frost and dust (in unknown and probably variable proportions) within the last few million

146 years during periods when Mars' axial tilt was higher than at present (e.g., Mustard et al.,

147 2001; Head et al., 2003; Schon et al., 2009; Madeleine et al., 2014).

148 Dundas et al. (2018) documented seven scarp exposure sites in the southern

149 hemisphere and one cluster in Milankovič crater in the north; Harish et al. (2020)

150 reported two additional scarps in the northern hemisphere. However, neither conducted a

151 comprehensive survey. Additionally, the number of known ice-exposing craters has more

152 than doubled since publication of Dundas et al. (2014). This work reports an assessment

153 of the locations and properties of ice-exposing scarps in current data in both the northern

154 and southern mid-latitudes and reports on the expanded data set of icy craters.

155

156 2. Methods

157 2.1. Data

158 The data sets used for this work included Thermal Emission Imaging System

159 (THEMIS; Christensen et al., 2004) Daytime Infrared mosaics, Context Camera (CTX;

160 Malin et al., 2007) images, and High Resolution Imaging Science Experiment (HiRISE;

161 McEwen et al., 2007) images. The THEMIS products use daytime infrared observations

162 and provide near-global mosaics at $100 \mathrm{~m} /$ pix (Fergason et al., 2019). CTX images have

163 near-global coverage at $6 \mathrm{~m} /$ pix. HiRISE images reprojected to 25 or $50 \mathrm{~cm} /$ pix cover

164 only a small fraction of the surface and include a central swath with two additional colors

165 (from blue-green and near-infrared filters) within the wider red-filter image. These

166 images were often targeted to center on the features studied here. We used HiRISE data

167 through Mars Reconnaissance Orbiter orbit 64,199 for study of icy craters and through 
168 orbit 66899 for icy scarps. We also inspected data from the Compact Reconnaissance

169 Imaging Spectrometer for Mars (CRISM; Murchie et al., 2007) where available. CRISM

170 is a visible and near-infrared spectrometer, which can provide more definitive evidence

171 for water ice than our other data sets, but observations are spatially limited and often do

172 not include the near-infrared wavelengths that provide the strongest evidence for ice. We

173 followed the same CRISM processing techniques used in Dundas et al. (2018).

174 Most HiRISE images include a near-infrared channel, so they do not detect the

175 same wavelengths as the human eye. Thus when displayed in color, they do not show true

176 colors. In the enhanced-color images shown in the figures herein (which are from

177 standard Reduced Data Records), the near-infrared filter data are displayed as red, the red

178 filter data are displayed as green, and the blue-green filter data are displayed as blue, and

179 the images are stretched to show local contrast and emphasize color variations; this is

180 standard procedure for HiRISE color products (Delamere et al., 2010). The stretch is

181 scene dependent for each observation, so conclusions about the apparent color of features

182 in different images depend on the scene having a similar range of colors and shadows.

183 This is often roughly true on Mars, where surface dust tends to be uniformly reddish.

184 However, differences in topography, atmospheric dust content, illumination, and

185 sublimation of ice can produce apparent differences in color between images as well as

186 color changes in unchanged parts of the surface when comparing images of the same site.

187 Both raw HiRISE data and calibrated top-of-atmosphere reflectance for each channel are

188 available via the Planetary Data System.

189 Materials that appear blue in stretched images may have a reddish true color but

190 are brighter than their surroundings in the HiRISE blue-green channel. Material that 
191 appears white is brighter in all three channels, but generally not white in true color. We

192 refer to these enhanced colors as "relatively blue" or "relatively white" in the text below.

193 Relatively blue or relatively white coloration is not diagnostic of exposed ice (notably,

194 mafic materials including basaltic sand also appear relatively blue (Keszthelyi et al.,

195 2008; Delamere et al., 2010)). However, we considered the combination of a relatively

196 blue or relatively white color closely associated with the distinctive morphology of a

197 scarp or new crater sufficient to classify a feature as an ice exposure with a high degree

198 of confidence. Changes over time often support the presence of ice, as described below.

200 2.2. Ice-Exposing Scarps

201 We conducted a survey of the distribution of ice-exposing scarps with the

202 properties described by Dundas et al. (2018). We searched the THEMIS Daytime Infrared

203 controlled mosaics (Fergason et al., 2019) at latitudes equatorward of $65^{\circ} \mathrm{N} / \mathrm{S}$ and the

204 uncontrolled global mosaic version 12.0 (e.g., Edwards et al., 2011) poleward of $65^{\circ} \mathrm{N} / \mathrm{S}$.

205 In the southern hemisphere, we searched latitudes $45-70^{\circ} \mathrm{S}$ (planetocentric), and

206 observed scarps only between $50-61^{\circ} \mathrm{S}$. Based on the results of this search, we limited

207 the northern-hemisphere survey to $45-65^{\circ} \mathrm{N}$. All scarps identified in the northern

208 hemisphere were between $53-59^{\circ} \mathrm{N}$, indicating that these bounds were sufficiently wide.

209 Further support for these bounds is provided by Vincendon et al. (2010), who searched

210 CRISM data and found no exposed perennial ground ice between $45^{\circ} \mathrm{S}$ and $50{ }^{\circ} \mathrm{N}$. We

211 looked for irregular pits greater than a few hundred meters across and checked candidates

212 using images from CTX to look for the main identifying characteristic of ice-exposing

213 scarps: an approximately straight, smooth, sharp-edged, pole-facing scarp (Fig. 1b). 
214 Candidates possessing such a scarp were classified as probable if no HiRISE color data

215 were available or considered confirmed if they displayed a distinct relatively blue

216 coloration in HiRISE images. In some of the cases from Dundas et al. (2018), spectral

217 evidence provides additional confirmation of water ice, but CRISM data are often not

218 available. An additional requirement was that coloration was present in late spring or

219 summer (no earlier than $L_{s}=70^{\circ}$ in the north or $L_{s}=250^{\circ}$ in the south, although in most

220 cases color data exist from after the solstice), to rule out lingering seasonal frost. The

221 precise duration of seasonal frost depends on latitude, slope, aspect, and substrate ( $c f$.

222 Vincendon et al., 2010; Dundas et al., 2019) but these bounds make seasonal frost

223 unlikely. Some sites were classified as confirmed but marginal. In these cases, the

224 morphology matched other scarps, but the coloration was weak or only occurred on a

225 small part of the scarp (Fig. 2a). Most scarps identified as candidates based on

226 morphology were confirmed to have at least some relatively blue coloration (in the cases

227 where HiRISE images exist), but some, particularly in Milankovič crater (Fig. 2b), have

228 coloration matching the surrounding terrain. The latter are likely to be exposures that are

229 partially or completely covered by an opaque coating of dust or debris, which is likely

230 thin since the morphology remains sharp. Alternatively, the ice at such scarps might

231 contain sufficient lithic material to suppress the coloration. Users of this data set may be

232 able to treat the probable scarps as confirmed if future HiRISE or other observations meet

233 the color criteria outlined above or yield spectral evidence of ice.

234 We considered the possibility that the scarps could be locations of year-round

235 frost stability rather than exposed subsurface ice. Frost on steep $\left(\sim 30^{\circ}\right)$ mid-latitude

236 slopes such as crater walls near $45^{\circ}$ latitude survives until $\mathrm{LS}_{\mathcal{S}} 40^{\circ}$ in the north and 
$237 \mathrm{~L}_{S^{\prime}} \sim 180^{\circ}$ in the south; near $55^{\circ}$, it persists until $\mathrm{L}_{\mathcal{S}} \sim 50^{\circ}$ and $\mathrm{L}_{\mathcal{S}} \sim 210^{\circ}$, respectively

238 (Vincendon et al., 2010; Dundas et al., 2019). Near the poles $\mathrm{H}_{2} \mathrm{O}$ frost survives into

239 summer on level ground (e.g., Appéré et al., 2011) and the very steep pole-facing scarps

240 have insolation roughly equivalent to the poles, although they receive more re-radiated

241 heat from other slopes. However, the scarps are erosional features, as they incise into and

242 remove surface material and have scarp-parallel ridges indicating past positions (Dundas

243 et al., 2018). Blocks falling from one scarp indicate an ongoing average retreat rate of

244 millimeters per Mars year (Dundas et al., 2018) and the same processes should act on

245 other scarps, which lack embedded rocks. Despite this, scarps retain relatively blue

246 coloration through the summer. Although some scarps possibly reach an equilibrium state

247 or even aggrade, the evidence that the scarps begin as erosional features, are actively

248 retreating at present, and yet retain the coloration of ice year-round is inconsistent with

249 persistent frost; the existence of morphologically identical scarps without icy coloration

250 also indicates that the scarp topography does not produce long-lived frost. Additionally,

251 CRISM band depth ratios at one scarp suggest coarse-grained ice rather than fine-grained

252 frost. Finally, scarp temperatures rise above the $\mathrm{H}_{2} \mathrm{O}$ frost point (Dundas et al., 2018).

253 Thus, although there might be occasional cases of persistent frost, exposed ice is the

254 dominant explanation.

255 The quality and completeness of the THEMIS mosaics are generally good, and

256 the area where scarp pits might have been obscured or lost in data gaps is small. We also

257 spot-checked many patches with deep shading from topography by examining CTX

258 images and did not find any examples of pits or scarps hidden in this way. We used CTX

259 data to more closely examine pits and scarps found in THEMIS mosaics that appeared 
260 consistent with the morphological criteria noted above. Those features are best seen when

261 kilometer-scale and larger, but smaller pits that appeared to match the morphology were

262 also inspected. Examination of hundreds of smaller or marginal-quality candidates gives

263 us confidence that the above criteria were effective in identifying scarps. Examining

264 every single pit or slope in the THEMIS-surveyed area at CTX resolution was not

265 practical. In regions of dense pitting such as scalloped terrain, we inspected those several-

266 hundred-meter scale features that appeared particularly sharp and distinct in the THEMIS

267 mosaics, and in the course of this survey we also examined large numbers of other pits

268 and slopes. This examination was sufficient to demonstrate that few scarps are not part of

269 the pits that are distinctive in the THEMIS IR mosaics, although some exist.

270 Additionally, survey results demonstrate that some scarps display gradations in

271 morphology. In aggregate, this survey likely includes nearly all sharply defined ice-

272 exposing scarps in the surveyed latitude zones that are near kilometer scale and larger.

273 This completeness scale is not well defined, but we estimate that it is between 500 meters

274 and 1 kilometer. Some smaller and less well-defined exposures are included here, but

275 more probably remain to be discovered. The two scarps reported by Harish et al. (2020)

276 were independently identified by our survey, supporting its effectiveness in identifying

277 scarps at these scales.

278 We measured scarp morphometric data in near-nadir HiRISE images.

279 Orthorectified images are not available for most sites, so precise geometric correction

280 was not possible and all dimensions are approximate, but for typical near-nadir viewing

281 geometry the distortion is small except on steep topography. Morphometric data include

282 the end-to-end straight-line distance, the greatest plan-view width, the estimated retreat 
283 distance (between the scarp face and any geomorphic indication of the initiation point),

284 and the orientation of a line connecting the scarp endpoints.

285 Only one site has a high-resolution digital terrain model (DTM) (Dundas et al.,

286 2018). For some sites where appropriate images exist, we made slope estimates using the

287 shadow method of Dundas (2017b). This method takes advantage of the fact that for a

288 given Sun position and slope azimuth, there is a unique slope angle at which the slope

289 begins to cast shadows. We identified locations on the brink of self-shadowing by

290 selecting sections of slope with patchy coverage by local shadows. This method has two

291 major limitations. First, for any given Sun position it can only indicate particular

292 slope/aspect combinations, which may not be representative of the whole scarp and

293 certainly do not capture local variability. This could also result in biases when comparing

294 between sites, since the available images might favor different slope/aspect combinations

295 at different sites. Second, the method requires manual estimation of the downhill

296 direction. This is challenging, especially on curved slopes, and results in large

297 uncertainties. This method gives good results when applied to the scarp with a

298 corresponding high-resolution DTM, but the inherent limitations must be considered in

299 interpretation. Directional distortion due to map projection is minor for standard HiRISE

300 images, which are reprojected in equirectangular projection with a center latitude near the

301 image center.

302 We also documented the presence or absence of several possibly related

303 geomorphic features in the vicinity of the scarps. These include scalloped depressions (cf.

304 Morgenstern et al., 2007; Soare et al., 2008; Lefort et al., 2009; 2010; Zanetti et al.,

305 2010), expanded craters ( $c f$. Dundas et al., 2015; Viola et al., 2015), and irregular pits, all 
306 of which may indicate sublimation and ice loss, as well as surface lineations indicative of

307 flow (cf. Squyres, 1978; Milliken et al., 2003). These features were documented if they

308 appeared on the same material unit as the scarp and were within 10-20 km distance. For

309 confirmed scarps with HiRISE coverage, we also documented smaller-scale features of

310 the scarp-hosting unit within hundreds of meters of the scarp crest. These included

311 polygons (interpreted as created by thermal contraction cracking; Mellon, 1997), surface

312 boulders, which are of interest since their occurrence on top of deposits potentially

313 originating as snowpack is surprising, and indications of layering exposed by the scarp,

314 which could preserve a climate record.

316 2.3. Ice-Exposing Craters

317 New impact locations are usually identified by manual searches of images from

318 CTX or other medium-resolution images, where they appear as dark markings due to

319 disturbance of surface dust (Malin et al., 2006; Daubar et al., 2013). This leads to a bias

320 towards detecting new impacts in high-albedo, low-thermal inertia (dusty) regions. These

321 detections are also dependent on having before-and-after imaging to constrain their

322 formation dates, and the availability of such imagery varies spatially and temporally.

323 Follow-up with higher-resolution imaging from HiRISE is usually needed to confirm the

324 presence of a crater and determine its size. In some cases at middle and high latitudes, the

325 new impacts reach deeply enough to excavate ice. The ice gradually sublimates, causing

326 excavated material to change color to match the nearby regolith over a period of months

327 to years (Dundas and Byrne, 2010; Dundas et al., 2014). Hence, only impacts formed

328 within the last few months or years are reliable probes for ice. Unfortunately, sublimation 
329 and the associated fading of the ice exposures are fastest at the lowest latitudes, where the

330 presence or absence of ice is least certain, implying that detection of ice is also least

331 efficient at those latitudes. At higher latitudes, the seasonal polar cap is particularly

332 effective at obscuring fresh impacts, as dark blast zones within the bounds of the seasonal

333 cap are erased within the first winter (Dundas et al., 2014) due to dust deposition or

334 redistribution, although ice sometimes remains distinct. Additionally, the dark markings

335 surrounding new impacts can fade within several Mars years, and more changes to the

336 blast zones are seen at higher absolute latitudes (Daubar et al., 2016), likely due to

337 seasonal processes, implying that the overall detections of new craters are less efficient at 338 high latitudes.

339 A strong theoretical and observational basis indicates that shallow ground ice is

340 almost ubiquitous poleward of $\sim 45-50^{\circ} \mathrm{N} / \mathrm{S}$ and rare equatorward of $\sim 30-35^{\circ} \mathrm{N} / \mathrm{S}$ (e.g.,

341 Mellon et al., 2004; Bandfield and Feldman, 2008; Pathare et al., 2018; Piqueux et al.,

342 2019), but the true boundary within that range is an unknown that can be tested with

343 observations of these craters. Therefore, we examined all new craters poleward of 35

$344{ }^{\circ} \mathrm{N} / \mathrm{S}$ and made an interpretation of the icy status based on the criteria discussed below.

345 We use HiRISE enhanced color observations as our primary means of determining

346 whether ice is likely exposed. The ice exposed by craters is bright and generally appears

347 relatively blue or relatively white in HiRISE enhanced color. Relatively white coloration

348 is uncommon in non-polar HiRISE images and with appropriate context can be highly

349 indicative of frost or ice. Relatively blue coloration can also be due to mafic materials

350 (Fig. 3a), but we treat it as indicative of ice when other evidence is strongly supportive of

351 this interpretation: i.e., the material is substantially brighter than surroundings rather than 
352 simply distinct in color. An additional indicator of ice is that material is distinct from

353 other ejecta and crater floor materials, suggesting that some ejecta is ice and some is ice-

354 free even if both are relatively blue. This is expected because the Martian surface is

355 mostly mafic, even when ice is present. For small exposures, the ice is often in discrete

356 patches with a distinct color relative to other excavated material. Other than the initial

357 decision to only examine craters above $35^{\circ}$, latitude was not used to interpret the

358 presence of ice, since the distribution of ice is not completely understood. Some material

359 interpreted as ice was slightly relatively yellow, but substantially brighter than the

360 surroundings and in settings where thermal contraction polygons also strongly support

361 the presence of subsurface ice. Possible ice with a relatively yellow coloration has been

362 reported in a gully alcove elsewhere on Mars (Khuller and Christensen, 2019), so this

363 coloration is consistent with the presence of ice as well.

364 CRISM can provide definitive spectral tests for ice in some cases where the

365 exposure is large enough (Byrne et al., 2009), but we do not use this as part of our

366 diagnostic process because most of the marginal cases are small (2-10 m diameter

367 craters) and unlikely to produce an unambiguous spectral signal in $18 \mathrm{~m} / \mathrm{pix}$ CRISM data.

368 In many cases appropriate CRISM observations do not exist. Three factors, however,

369 support a general interpretation of the impact features meeting these color criteria as icy,

370 rather than exposed salts or other bright lithic material: (1) CRISM confirmation of ice at

371 several sites that share the indicators that we use for ice (Byrne et al., 2009); (2) lack of

372 spectral detections of other materials that might account for the bright deposits; and (3)

373 fading and disappearance over time consistent with sublimation at many of these sites

374 (Dundas and Byrne, 2010; Dundas et al., 2014). Since there is a strong theoretical basis to 
375 expect ice at these latitudes and cryogenic landforms are common around the craters, this

376 is the simplest interpretation; as discussed below, our diagnostic criteria are likely

377 underestimating the occurrence of ice.

378 We also note candidates where we consider the evidence for ice to be less

379 compelling. These are divided into (1) probable ice, where ice is our preferred

380 interpretation but not considered definitive due to very small size, weaker color contrast

381 with other ejecta, or lack of a well-defined crater; and (2) possible ice, where there is a

382 small color feature in the crater with minor contrast, or a bright feature that could be due

383 to topographic effects. Some sites initially classified as possible or probable were later

384 elevated to confirmed if the candidate exposure became less distinctive over time in a

385 manner consistent with sublimation and lag development (i.e., a color feature reverting to

386 match adjacent surfaces more quickly than the general fading of the blast zone).

387 Some low- and mid-latitude impacts (e.g., Fig. 3b) expose relatively bright

388 material that contrasts with a dark surface but is not interpreted as icy. Few of these exist

389 in our study latitudes. The surface geomorphology surrounding these sites generally does

390 not suggest ice (in particular, no polygons are interpreted as thermal contraction cracks).

391 Most of these craters occur at low latitudes $\left(<35^{\circ}\right)$ outside our survey area, where

392 theoretical models suggest that shallow ice is unlikely (e.g., Mellon et al., 2004).

393 Additionally, most or all of the ejected material is bright rather than isolated patches. At

394 low latitudes ice should be covered by a significant thickness ( $>1 \mathrm{~m})$ of regolith or it

395 would otherwise sublimate rapidly, so if there were ice, it would occur in the ejecta as a

396 mix of ice and non-icy regolith. These bright ejecta deposits may be similar to exposures

397 of bright material by rover wheels in Gusev crater (e.g., Rice et al., 2011) or other 
398 surface/subsurface compositional or grain size differences. While these craters provide

399 information about the Martian subsurface, they are not considered further in this

400 discussion of subsurface ice.

401 The icy craters that we document are those that expose persistent bright ice that 402 remains distinct for months to years while sublimating, indicating clean ice with a low

403 lithic content. Some apparently non-icy craters may have exposed subsurface pore ice,

404 which would be all but impossible to detect from orbit. As shown by the Phoenix lander

405 excavations, exposed pore-filling ice is dark, and in summer at mid-to-high latitudes it

406 sublimates enough to create a surface coating that is indistinguishable from regolith

407 within days (Mellon et al., 2009; Smith et al., 2009). This is much shorter than the typical

408 time between the impact and acquisition of HiRISE images. Candidate impacts at high

409 latitude are usually imaged by HiRISE within weeks of the initial detection in lower-

410 resolution images, but that initial detection can be one to several years after the crater

411 formed. One caveat is that the impact process may generate fractures and fine-grained

412 material, which would be brighter than the pore ice exposed by the Phoenix lander, but a

413 small amount of sublimation would still quickly produce an opaque cover under those

414 conditions. Additionally, the small size of many of these craters means their shallow

415 depths of only tens of centimeters may not be enough to reach the ice table. Finally, at

416 high latitudes the seasonal cap reworks the surface, removing blast zones and obscuring

417 ice, which can preclude detection and confirmation if craters are not imaged or re-imaged

418 before winter. Thus, the set of craters we consider confirmed ice exposures are a

419 minimum, and subsurface ice could exist at other known or unknown impact locations. 


\section{3. Scarp Observations}

422 The full set of scarp exposures is given in Tables S1-S2 and mapped in Fig. 4.

423 Below, we discuss some relevant morphological and geographical observations.

425 3.1 Scarp Distribution

426 In the southern hemisphere, 21 confirmed exposure sites were identified in the

427 southern hemisphere (some with multiple scarps), along with two candidates lacking ice

428 coloration, and one for which no HiRISE color data were available at the time of writing.

429 The southern-hemisphere scarps are confined to a narrow range of longitudes near the

430 Hellas basin, not evenly distributed throughout the latitude band. Most of the exposures

431 are between $80-115^{\circ} \mathrm{E}$ longitude and 50-61 ${ }^{\circ} \mathrm{S}$ latitude, similar to those previously

432 known. A few occur in scalloped terrain ( $c f$. Zanetti et al., 2010) at 50-61 ${ }^{\circ} \mathrm{E}$ and a small

433 cluster near $137^{\circ} \mathrm{E}$.

434 Scarps in the northern hemisphere are strongly concentrated in the mantling

435 deposits within Milankovič crater $\left(54.5^{\circ} \mathrm{N}, 213.5^{\circ} \mathrm{E}\right)$, which we subdivided into four

436 sites in Table S1 based on the four cardinal directions. Over 70 features have the

437 morphology of ice-exposing scarps at this location, although in HiRISE data some lack

438 the relatively blue coloration indicative of exposed ice. Beyond Milankovič, a handful of

439 scarp sites occur in crater-fill materials farther east, and one occurs in northern Utopia

$440 \quad$ Planitia $\left(96^{\circ} \mathrm{E}\right)$. 
444 subparallel faces (Fig. 5) or are divided into adjacent segments. Many exhibit faint, crude

445 layering or color banding, but distinctive sub-meter-scale layers are uncommon (Fig. 6).

446 Scarp lengths range from $200 \mathrm{~m}-6.5 \mathrm{~km}$, and plan-view scarp widths range from 20-200

447 m. Length, width, and estimated retreat distance are loosely correlated (Fig. 7a, b).

448 Latitude appears to weakly influence the upper envelope of scarp retreat distance, with

449 somewhat greater scarp retreat at lower latitude (Fig. 7c). This may indicate active

450 formation of new scarps, coupled with faster retreat at lower latitudes, because retreat

451 distance should be a function of scarp age and sublimation rate. The latter will be

452 influenced by latitude. However, the ratio of scarp length to retreat distance (the plan-

453 view aspect ratio of the pits) shows no trend with latitude (Fig. 7d). This aspect ratio

454 indicates the extent to which the scarp widens as it retreats. All scarps in both

455 hemispheres approximately face the pole but most are oriented slightly east of due

456 poleward, with a typical offset from N/S of 5-10 ${ }^{\circ}$. This offset could relate to

457 morning/afternoon asymmetries in temperature combined with the thermal inertia of the

458 surface reducing peak temperature. Individual scarps have along-scarp orientation

459 variations on the same order as this offset.

460 The one scarp for which high-resolution topographic data exist (southern scarp

461 \#1) has typical slopes of $\sim 45^{\circ}$ with moderate variations both vertically and laterally

462 (Dundas et al., 2018). Shadow-derived estimates at four locations on this scarp are 47-

$46349^{\circ}$, demonstrating that the method gives reasonable results for typical scarp geometry.

464 Shadow-derived slope estimates for other scarps with appropriate shadow conditions are

465 given in Table S3. In the southern hemisphere, slopes range from $41-60^{\circ}$, with most 
466 between $45-50^{\circ}$. In the north, a variety of confirmed and candidate exposures have slopes

467 of $40-64^{\circ}$. The mean slope in the north $\left(53^{\circ}\right)$ is similar to that in the south $\left(49^{\circ}\right)$. These

468 estimates suggest that southern scarp \#1 is typical. These slopes indicate that the plan-

469 view widths of the scarps approximate the vertical relief to within a factor of 2.

470 Furthermore, the pits do not necessarily reach all the way to the bottom of the ice, so the

471 ice thicknesses may be even larger.

$472 \quad$ As reported in Dundas et al. (2018), scarp-parallel features indicate that scarps

473 retreat generally equatorward and that retreat is uniform along the length of the scarp.

474 Triangular or other shapes of the resulting pits indicate that the scarp width can vary over

475 time (Fig. 8). Scarp retreat appears to be close to uniform along the length of the scarp,

476 such that when the retreat direction is oblique rather than normal to the scarp, the

477 orientation of the scarp remains unchanged (Fig. 8). Notches in the plan-view shape of

478 pits (Fig. 8) suggest that scarp retreat occasionally reactivates only over part of its length;

479 the other parts may reactivate later, giving rise to the small parallel outliers seen in some

480 pits. The aspect ratio of the scarp pits shows substantial scatter (Fig. 7d), so the rate at

481 which scarps widen as they retreat is highly variable.

482

$483 \quad 3.3$ Scarp Setting

484 The regional properties of the locations are broadly similar in both hemispheres.

485 All of the identified scarps occur within deposits that appear to mantle the regional

486 surface (Fig. 9); although in a few cases, the uppermost part of the mantling deposit may

487 have been removed (Fig. 9c). In the southern hemisphere, the kilometer-scale regional

488 slopes around the scarps and pits are mostly pole-facing but generally low (typically $\sim 5^{\circ}$ 
489 in the Mars Orbiter Laser Altimeter digital elevation model), and some are nearly flat.

490 The scarps there are often associated with the slopes of few kilometer-scale local massifs

491 or crater walls. In the northern hemisphere, the vast majority of scarps and candidate

492 scarps are in Milankovič crater. They are found on all slope orientations therein, but

493 primarily on the west side of the crater (Fig. 10). As in the south, the regional slopes are

494 generally low. The material on the slopes of the crater may have a low density (at least

495 within the upper 5 meters) as it has a low radar surface reflectivity (Morgan et al., 2020).

496 The other northern-hemisphere candidates are found within materials that infill few

497 kilometer-scale impact craters. The regional albedos from the Thermal Emission

498 Spectrometer (TES; Christensen et al., 2001) are all close to 0.2, and the regional

499 apparent thermal inertias from TES (Putzig and Mellon, 2007) are between 128-225 J m ${ }^{-2}$

$500 \mathrm{~K}^{-1} \mathrm{~s}^{-0.5}$, consistent with a surface layer of unconsolidated dry soil a centimeter or more

501 deep, with the sole exception of the site in Utopia.

502 Although the scarps are characteristically within mantling deposits, the associated

503 geomorphology is variable. Candidate ice-loss features (scalloped depressions and

504 expanded craters) are found near some of the scarps, but in most cases the landforms are

505 not well-defined examples. However, irregular pits that do not closely match the

506 scalloped or expanded morphologies are almost ubiquitous across the scarp-hosting

507 mantling deposits. Arcuate lineations indicative of ice flow are uncommon. In the plateau

508 material at the top of the scarp, polygons (likely due to thermal contraction of ice) are

509 common but not ubiquitous, and often not well defined, which may indicate that the ice is

510 deep enough to not experience strong thermal cycles or that it anneals effectively without

511 infall of material into the cracks. In some cases the surface material consists of aeolian 
512 bedforms and so may currently be too mobile to develop defined polygons. The brink of

513 the scarp is often broken into blocky fragments that might be defined by subtle polygonal

514 fractures that have generated little surface relief. Polygons are also common on the walls

515 and floors of some pits. The upper surface of the scarp-forming material usually has few

516 boulders, particularly in the northern hemisphere.

$517 \quad$ CRISM data confirm exposed ice at several scarps (Table S1) beyond those

518 described in Dundas et al. (2018). Detections at two of the scarps were independently

519 confirmed by Harish et al. (2020). Notably, one observation of the icy scarp at $57^{\circ} \mathrm{N}$,

$52095.7^{\circ} \mathrm{E}$ (northern scarp site \#4) shows a distinct water ice signature, as well as an

521 ambiguous spectral signature in the visible to near-infrared, suggesting impure ice. The

522 simultaneously acquired HiRISE image shows only a weak color signature covering parts

523 of the scarp, leading to a classification of confirmed but marginal. This suggests that all

524 scarps with the classic morphology could be ice exposures, regardless of coloration.

525 Either the covering lag is too thin to completely suppress the ice spectral signature or the

526 lithic content of the ice is high enough in some cases that the coloration seen in HiRISE

527 is minimal. If the coloration is from a lag coating, it must be very thin, as a dust coating

528 of tens of microns can be opaque at visible wavelengths (Wells et al., 1984; Fischer and

529 Pieters, 1993). If the coloration reflects the bulk ice composition, this is still consistent

530 with a high ice content. Cull et al. (2010) show that for as little as 10 weight $\%$ lithics

531 (>95 volume \% ice) the visible color contrast may be minimal, and Clark and Lucey

532 (1984) showed substantial darkening and weak spectral absorption features for even

533 smaller amounts of non-ice material, depending on its albedo. Further monitoring with

534 HiRISE might distinguish between these possibilities, as lags could be removed 
535 episodically. Harish et al. (2020) also noted some scarps at northern scarp site \#5 with

536 relatively blue coloration but no spectral signature of ice, likely because the scarps were

537 substantially shadowed.

538 Numerous pits were examined and determined not to meet the morphological

539 criteria for likely ice exposures. Some of these may be former scarps that have become

540 buried under sublimation lags that are thick enough to obscure the sharp morphology of

541 clean exposures. Examples of pits without distinct scarps are shown in Fig. 11 for

542 comparison, and Fig. 8 shows a pit that mostly lacks exposures apart from a small outlier

543 scarp.

544

545 4. Crater Observations

546 HiRISE images now cover 48 ice-exposing impact sites (Fig. 12 and Table S4).

547 The diameter of ice-exposing and non-ice-exposing craters poleward of $35^{\circ} \mathrm{N} / \mathrm{S}$ is shown

548 in Fig. 13. Diameter scales linearly with maximum excavation depth for small craters

549 (Melosh, 1989), and Fig. 13 also shows $0.084 \times$ the crater diameter. This value is given

550 since the maximum excavation depth is $\sim 1 / 10$ of the transient crater diameter and the

551 transient crater is $\sim 0.84 \times$ the final diameter for simple craters (Melosh, 1989); although

552 seemingly precise, this depth should only be treated as an approximation. The data set is

553 more extensive than that in Dundas et al. (2014) but is broadly similar and does not

554 change the interpretations made therein. Those include the widespread occurrence of

555 clean ice with local heterogeneity, as well as the latitudinal distribution in the northern

556 hemisphere, which suggests that the long-term atmospheric water vapor content was

557 higher than at present and/or that there is a near-surface concentration of vapor. The 
558 morphology of the ice exposures ranges from small fractions of the crater interior to

559 extensive icy ejecta. Several important new observations and their interpretations are

560 discussed below.

561 Weak material over a strong layer produces characteristic crater morphologies of

562 flat floors and benches or terraces for craters with diameters approximately 4-10 times

563 the weak layer thickness (Quaide and Oberbeck, 1968). The depth to the strong layer can

564 be estimated using the methods of Bart (2014). For sites with exposed ice, there is a high

565 likelihood that such a strong layer is the top of the ice table since the ice is known to exist

566 and should provide a strength contrast. We apply this method at sites with multiple flat-

567 floored craters. Those craters are often not the same as those with visible ice, since the ice

568 exposures tend to be in the largest craters that penetrate more deeply into the ice table.

569 (For sites without confirmed bright ice, the morphology could be produced by pore ice

570 but also by shallow bedrock or another strength contrast, making the interpretation less

571 certain.) The results (Table 1) show significant variability in depth to the strong layer

572 between different craters in individual clusters. This likely reflects both real local depth

573 variation and measurement uncertainty. In combination with differences in the visibility

574 of ice in similarly sized craters (Dundas et al., 2014), this indicates that heterogeneities in

575 the ice table depth and ice content are significant at scales of tens to hundreds of meters.

$576 \quad$ Fewer new craters (icy or not) have been discovered in the southern hemisphere

577 in comparison with the north, mainly because the less extensive dust cover in the south

578 inhibits detection, but also due to different imaging and search techniques that vary by

579 region. The distribution is still sufficiently sparse that the southern latitudinal boundary is

580 not well defined. However, the number and distribution of icy impacts observed in the 
581 southern hemisphere has expanded significantly relative to Dundas et al. (2014), and the

582 lowest-latitude ice detection in the south is now at $46.2^{\circ} \mathrm{S}$. That crater is on a slight pole-

583 facing slope with nearby gullies and thus may not be representative of level ground, but

584 there is also a probable candidate on flat ground at $42.6^{\circ} \mathrm{S}$.

$585 \quad$ In the northern hemisphere, the lowest-latitude detection remains at $39.1^{\circ} \mathrm{N}$. This

586 location is part of a southward excursion of icy crater detections extending between

$587 \sim 145-205^{\circ} \mathrm{E}$ where ice detections are common between $40-50{ }^{\circ} \mathrm{N}$ (Fig. 12). This

588 contrasts with a lack of confirmed icy craters at those latitudes between $205-255^{\circ} \mathrm{E}$. The

589 region lacking icy craters corresponds to terrain where stability models predict that ice

590 should be quite shallow and extend particularly far towards the equator due to high

591 albedo and low thermal inertia (Mellon et al., 2004), so it is possible that pore ice is

592 dominant at the top of the ice table there. Some of the non-ice-exposing craters in this

593 area have flat floors which could indicate such a pore ice table, but this interpretation is

594 nonunique. At other longitudes, new crater detections between $40-50^{\circ} \mathrm{N}$ are sparse, and

595 the only other ice detections equatorward of $47.4^{\circ} \mathrm{N}$ are on lineated valley fill; these

596 detections may not indicate extant ice under the surface in those areas apart from within 597 the lineated valley fill.

598 Two craters near Protonilus Mensae excavated lineated valley fill and confirm the 599 presence of ice within a few meters of the surface there between $41-42^{\circ} \mathrm{N}$ (Fig. 14). This 600 could be the top of glacial ice that has been detected in similar material by the Shallow 601 Radar (SHARAD; Holt et al., 2008; Plaut et al., 2009; Petersen et al., 2018), the top of 602 which is not detectable at SHARAD resolution (approximately $10 \mathrm{~m}$ in ice); however, 603 ice-rich lenses or other structures within a thicker debris cover cannot be ruled out. In the 
604 eastern part of the crater shown in Fig. 14a, ice exposed in the crater wall appears to

605 make up the core of a surficial topographic ridge (a part of the surface type sometimes

606 referred to as "brain-coral" or "brain" terrain (e.g., Noe Dobrea et al., 2007; Levy et al.,

607 2009b)) that was cut by the impact, providing information about the subsurface structure

608 of such material. In both of these craters the visible ice exists mostly in discrete blocks, in

609 contrast with most others; this suggests that the shallow subsurface ice is in discrete

610 bodies surrounded or covered by ice-free debris, which may indicate that ice at these

611 locations is unstable and sublimating, since ice would be expected to cement the regolith

612 pore space at these depths if it were stable.

613 Polygons attributed to thermal contraction cracking (e.g., Mellon, 1997) are

614 nearly ubiquitous at the sites of ice-exposing impacts. They are occasionally found

615 around new impacts where HiRISE images do not show bright ice but much less

616 frequently. At some of those sites impacts probably exposed pore ice or did not excavate

617 to the depth of the ice table. This suggests that thermal-contraction polygons and present-

618 day ice are strongly correlated and that relict ice-free polygons are uncommon. However,

619 the morphology of the polygons is diverse, including high-centered and low-relief

620 features, irregular or incomplete polygon networks, as well as regularly spaced low-relief

621 hummocks without defined fractures. Thus, the relationship between the detailed polygon

622 morphology observable at HiRISE resolution and the presence of excess ice is not simple,

623 but ice-exposing craters are sparse and offer limited information about the vertical

624 structure of the ice.

625 An 18 m-diameter crater that formed on the south polar layered deposits (SPLD)

626 during southern winter of Mars Year 34 showed minimal bright ice once the seasonal 
627 frost had vanished (Fig. 15ab) and was classified as probable. This crater is discussed

628 more extensively in Landis et al. (2020). A second crater cluster in the southern mid-

629 latitudes has been observed to form with ejecta superposing seasonal frost (Fig. 15c).

630 This site also lacks bright ice once defrosted, but the craters are much smaller and may

631 not have excavated to ice. In both cases the crater morphologies appear minimally

632 affected by the presence of $\mathrm{CO}_{2}$ frost at the time of impact, demonstrating that seasonal

633 frost probably has little effect on the long-term cratering record except for extremely

634 small craters.

635 The SPLD and Protonilus craters also enable us to assess whether any of the

636 observed bright ice is due to melting/refreezing ( $c f$. Reufer et al., 2010) or condensation

637 of vapor post-impact, rather than representing the original state of ground ice. If the

638 former were the case those effects would be expected to be strongest in the largest

639 craters, which represent the most energetic impacts. Small bolides should be slowed by

640 the atmosphere and their small craters should have little if any melting, so we can rule out

641 the possibility of impact generation of clean ice if it does not occur in the larger craters.

642 The $18 \mathrm{~m}$ crater on the SPLD (Fig. 15a, 15b) is larger than most lower-latitude craters

643 with visible ice exposures but has negligible amounts of bright ice. The SPLD certainly

644 contains significant ice content in bulk (at least 85\%; Plaut et al., 2007; Zuber et al.,

645 2007) although the near surface could be pore-filling ice, and theory indicates that ice

646 should begin at depths of centimeters there (e.g., Mellon et al., 2004). Likewise, discrete

647 ice blocks occur around the largest ice-exposing crater (Fig. 14a) as well as several

648 others. Long-baseline temporal monitoring of several craters demonstrates shrinking and

649 disappearance of blocks of ejected ice, as reported at other sites by Dundas et al. (2014), 
650 suggesting that the blocks are massive ice. These blocks are inconsistent with melt pools

651 or condensation. Thus, several of the largest ice-exposing craters have characteristics that

652 show that the bright ice is not produced by the impact process. This implies that the

653 observed clean ice represents the natural state of the pre-impact ice for most or all craters.

654 High ice contents (well above pore-filling) are widespread in the shallow subsurface at

655 latitudes above $\sim 40^{\circ} \mathrm{N}$.

656 Only five of the confirmed ice-exposing impacts have an $\mathrm{H}_{2} \mathrm{O}$ ice signature in

657 CRISM data (Table S4), while 23 have CRISM data without an ice detection. All five are

658 among the larger craters or clusters of several craters and have large swaths of ice in their

659 ejecta rather than small exposures in the crater itself. In some locations, we also analyzed

660 repeat CRISM observations, but the absorption bands attributed to water ice were weak

661 and barely detectable above the noise. Either atmospheric haze, accumulated surface dust,

662 or spectral mixing and signal being averaged into multiple pixels precluded detection of

663 ice in the later CRISM images after the initial observation. This demonstrates that

664 extensive areal exposures and contemporaneous observations are required for ice

665 detection by CRISM, as even the largest ice exposures only occupy portions of a handful 666 of pixels.

667

668 5. Discussion

669 5.1. Importance of Subsurface Ice Exposures

670 These surveys of scarps and craters directly provide information about the nature

671 and distribution of subsurface ice on Mars. They also provide an extensive set of

672 locations that can be used for validation of the presence and properties of ice indicated by 
673 other data and models. While they have not been studied in situ, these locations provide

674 more direct and localized information on the state of the ice than other methods currently

675 available. This level of verification and detail is useful for interpreting other data sets

676 (e.g., Pathare et al., 2018; Piqueux, et al., 2019), for design of possible ice-detection

677 instruments (e.g., Haltigin et al., 2018), and for the possible use of ice by human

678 explorers ( $c f$. Heldmann et al., 2014; Putzig et al., 2020).

679 Both the craters and scarps provide information about the local state of the ice

680 table, but the difference in the nature of the exposure and exposure process poses

681 challenges for analyzing the two together. For instance, impact-exposed ice is often

682 relatively white while the scarps are generally relatively blue. This may indicate some

683 degree of impact modification (e.g., fracturing reducing the grain size or increasing

684 porosity). Additionally, these differences in relative color could in part be related to the

685 surrounding terrain. Quantitative photometry including assessment of topography and

686 atmospheric scattering is needed before such color differences can be confidently

687 interpreted. The craters represent semi-random samples (subject to detection biases),

688 while certain regions or certain ice properties may be conducive to scarp formation, as

689 discussed below. Finally, different properties are measurable for each: for instance,

690 craters primarily provide information on the depth to ice. Scarps place lower bounds on

691 the ice thickness, but the depth to the top of the ice may be obscured by material falling

692 from the scarp crest. Despite this, in some places ice, can be seen within $1 \mathrm{~m}$ of the scarp

693 crest (Dundas et al., 2018) and could be exposed by craters.

694 The expanded surveys presented here are generally consistent with previous

695 interpretations of the state and distribution of ice based on a more limited sampling of 
696 features (Dundas et al., 2014; 2018). The larger data sets presented here do provide

697 several new insights into the origins, properties, and distribution of subsurface ice,

698 discussed in the following sections.

699

700 5.2. Distribution, Properties, and Origins of Subsurface Ice

701 The lowest-latitude detection of ice based on craters is unchanged in the north

702 compared with Dundas et al. (2014). Exposure of clean ice by new impacts is common,

703 indicating that such ice is widespread at shallow depths. The poleward-shallowing trend

704 of ice in crater exposures reported by Dundas et al. (2014) is confirmed by the additional

705 data reported here, with depth and latitudinal boundary similar to theoretical predictions.

706 Poleward of $\sim 50^{\circ} \mathrm{N} / \mathrm{S}$ latitude, most dated new impacts either definitely or possibly

707 expose bright ice. In crater clusters the larger craters generally expose bright ice and the

708 smaller ones do not (Table S4), but in several instances this relation is reversed. The

709 latter requires lateral heterogeneities in the distribution or concentration of ice in the

710 upper meter of the subsurface or variable impact properties and distribution of ejecta. The

711 depth to ice also has significant local variability when measured within crater clusters

712 (Table 1), consistent with theoretical predictions (Sizemore and Mellon, 2006) and

713 excavations by the Phoenix lander (Mellon et al., 2009).

714 The apparent variation in icy crater detections between $40-50^{\circ} \mathrm{N}$, from frequent

715 icy craters between $145-205^{\circ} \mathrm{E}$ to a lack at $205-255^{\circ} \mathrm{E}$, corresponds with features in

716 several other data sets. This zone of low-latitude icy craters corresponds to a region

717 where neutron spectroscopy shows high ice content (greater than pore-filling) extending

718 to lower latitudes than in the rest of the northern hemisphere (Pathare et al., 2018). The 
719 transition near $205^{\circ} \mathrm{E}$ approximately matches the transition from abundant expanded

720 craters (to the west) to few (to the east) in the mapping of Viola et al. (2015), although

721 that map has little coverage west of $190^{\circ} \mathrm{E}$. Viola and McEwen (2018) show that

722 expanded craters equatorward of $40^{\circ} \mathrm{N}$ are concentrated between $185-205^{\circ} \mathrm{E}$. The zone

723 of icy craters also corresponds to radar detections of a low dielectric constant (interpreted

724 as indicating a high ice content extending to tens of meters depth), which are

725 concentrated between $180-215^{\circ} \mathrm{E}$ (Bramson et al., 2015) and interpreted as a regional ice

726 sheet. The high bulk ice content of this unit has been challenged based on radar loss

727 tangent estimates (Campbell and Morgan, 2018), but the agreement of the ice exposures

728 and neutron spectroscopy suggests that at least the upper centimeters of the material are

729 ice-rich, which is further supported by the observation of expanded craters (Dundas et al., 730 2015).

731 A similar ice sheet has been proposed in the Utopia region (Stuurman et al., 2016)

732 based on mapping of radar reflectors that indicated a dielectric constant similar to that of

733 ice. No new impact detections are in the region of radar reflectors mapped by Stuurman

734 et al. (2016), likely because a lack of surface dust makes such detections rare (Fig. 12).

735 However, one ice-exposing crater is within the broader geomorphic unit of mesas and

736 scalloped depressions (Kerrigan, 2013) that contains the reflectors. Such scalloped

737 depressions have been attributed to partial sublimation of an ice-rich unit (e.g.,

738 Morgenstern et al., 2007; Lefort et al., 2009; Zanetti et al., 2010; Dundas et al., 2015), the

739 top of which may be indicated by the crater exposure.

740 Scarp exposures provide relatively weak constraints on the global distribution and

741 properties of ice on Mars, since they are at higher latitudes than many of the craters and 
742 may not reflect the typical state of shallow subsurface ice. However, they provide

743 important constraints on local properties. The scarps generally occur in surface-mantling

744 deposits. Mantling deposits that have been interpreted as ice-rich are common at middle

745 to high latitudes (e.g., Mustard et al., 2001; Head et al., 2003; Milliken et al., 2003;

746 Schon et al., 2009); the scarp regions appear somewhat more extensively mantled than

747 other areas, but this is difficult to quantify. The fact that scarps occur only in a narrow

748 latitude band in both hemispheres suggests that some process controlled by latitude is

749 important to exposing the ice, meaning that similar ice could exist elsewhere. However,

750 since the scarps are concentrated at certain longitudes while ground ice is expected to be

751 ubiquitous at these latitudes (e.g., Mellon et al., 2004; Schorghofer and Aharonson, 2005;

752 Chamberlain and Boynton, 2007), some other factor(s) relating to the state of ice or the

753 physical processes exposing it is also necessary to explain the scarp distribution. These

754 observations can be explained if ice exposures occur within a subset of mantling deposits

755 where ice is particularly thick and/or pure, providing longitudinal or local control, and if

756 particular latitudinal conditions (e.g., insolation and temperature) are required to create

757 and maintain the exposure. Supporting this possibility, the scarps in the southern

758 hemisphere are mostly located in longitudes where neutron spectrometer data show high

759 ice contents (60-90 weight percent) extending to relatively low latitudes (Pathare et al.,

760 2018). The same region also overlaps the location of the largest concentration of

761 scalloped depressions and thermokarst landforms in the southern hemisphere (Zanetti et

762 al., 2010; Viola and McEwen, 2018), also consistent with high ice contents. Scarps and

763 their host mantling units often appear localized near massifs or crater walls, which might

764 help concentrate snow deposition in incipient glaciers, but these correlations with other 
765 data sets suggest that the scarp-hosting ice bodies are associated with high regional ice

766 contents. In this interpretation, the ice at the exposures represents an ice-rich end-member

767 of the diversity of Martian near-surface mantling and ice deposits. Fully testing this

768 hypothesis requires more information on the state of ground ice at locations without

769 scarps; crater exposures are too shallow to provide a full comparison.

770 The ice exposed in the scarps likely originated as snow or frost, which has now

771 been compacted. This is based on two main lines of evidence. First, the hosting units

772 typically drape the surface in a manner consistent with atmospheric deposition rather than

773 infilling topographic lows, and the scarp properties imply a very low lithic content

774 (Dundas et al., 2018). Second, the fine crosscutting layers observed at some scarps (Fig.

775 6) are most consistent with snow, since subsurface growth of ice lenses or other

776 structures (e.g., Sizemore et al., 2015) would likely parallel the surface and not produce

777 crosscutting relationships. (This could arise within an airfall deposit that was partially

778 eroded and then covered, but the high ice content (Dundas et al., 2018) is better explained

779 by snow or frost.) Moreover, non-snow theories for the development of high subsurface

780 ice contents on Mars, such as ice lens growth or enhanced vapor diffusion (e.g., Fisher,

781 2005; Sizemore et al., 2015) operate in the near surface rather than building units $>100 \mathrm{~m}$

782 thick.

783 The presence of boulders on the surface of scarp-hosting units was noted as a

784 puzzle by Dundas et al. (2018). If the massive ice deposits are consolidated snow, they

785 should lack clasts larger than windblown sand or dust. The additional scarps included in

786 this larger sample set mostly exhibit few or no surface boulders at the top of the unit. This

787 observation is more favorable for a snowpack model than are abundant boulders, but the 
788 presence of any large rocks remains a puzzle. Rocks can be concentrated by sublimation

789 processes (Aylward et al., 2019), but must be present initially. Indications of glacial-style

790 flow are rare at these locations, so rafting to concentrate rocks at the surface may be an

791 insufficient explanation for boulders superposing the ice. An alternative is that boulders

792 are lifted and held at the surface during ice accumulation (Schorghofer and Forget, 2012),

793 but boulders are embedded within ice at one scarp (Dundas et al., 2018). A similar

794 process of locking boulders within seasonal $\mathrm{CO}_{2}$ frost and moving them via differential

795 thermal contraction is a possible explanation for horizontal boulder sorting at other

796 locations (Orloff et al., 2013). An additional possibility is that these surface boulders are

797 ejecta from nearby impact craters, although the sparse craters on the surface of the

798 mantling deposits suggest that impacts since those deposits were emplaced were not

799 sufficient. The scarps surveyed here are distinctly different from the steep slopes at the

800 edge of the north polar layered deposits (NPLD), which have slopes up to $70^{\circ}$ over 300 -

801 meter baselines and are approximately vertical over some shorter intervals (Russell et al.,

802 2008). These slopes also occur in a body of ice with low dust content, estimated to be

$803<2 \%$ (Picardi et al., 2005). Despite active avalanching and slope retreat (Russell et al.,

804 2008), the NPLD scarps generally have dusty coloration except on the flat residual cap

805 (Byrne, 2009), although because this is inferred from relative color, quantitative

806 inferences about the ice content are difficult.

807 In comparison with the scarps, the craters provide relatively little constraint on the 808 deposition and modification processes of the ice. They demonstrate the widespread

809 occurrence of processes that create high ice contents in the shallow subsurface, but the 810 small penetration depth and exposure size, and disruption of the ice by impact, make it 
811 difficult to distinguish between the various candidate processes. Boulders are common

812 around many of the craters, as at the scarps.

813

\section{5.3. Scarp Formation and Evolution}

815 The scarps pose a significant puzzle: how is the bare ice exposure created and

816 maintained, when a covering lag is expected to develop within years and sublimation is

817 actively occurring? Landscape evolution modeling suggests that a steep exposure of

818 dusty ice would gradually become shallower because the base would be buried under the

819 debris released by its own sublimation and retreat (Dundas et al., 2015). The straight

820 geometry of the scarps may reduce this effect because the debris at the base is not

821 collected from a wide area. The scarps are quite steep and could shed debris rather than

822 accumulating a surface cover, like the steep slopes of parts of the NPLD (Russell et al.,

823 2008). This appears to be occurring in some cases, but in at least one example the process

824 is building a debris-covered lower slope and deactivating sublimation on the lower scarp

825 (Dundas et al., 2018). Some scarps may be partially or completely debris covered (Figs.

$8262 \mathrm{~b}, 8,11)$, so in some conditions this process may cease. Additionally, how such a slope

827 is created in the first place or how scarps reactivate after accumulating surface debris is

828 not obvious. The scarps do not resemble impact features, which are typically circular, but

829 runaway growth from small impacts is a possibility. Fault movement can be ruled out at

830 one location by a lack of vertical offset (Dundas et al., 2018), and at no site is there any

831 indication of fault-like deformation extending beyond the scarp. Additionally, ridges

832 indicating scarp retreat are inconsistent with movement on a fault. The scarps face the 
833 pole regardless of the slope orientation and sometimes occur on level surfaces, which

834 rules out any gravity-driven failure.

835 Two possible factors in creating and maintaining scarps are seasonal frost and

836 aeolian transport. $\mathrm{CO}_{2}$ frost can transport material either via basal sublimation (e.g.,

837 Kieffer, 2007; Pilorget and Forget, 2016) or by loading a steep slope and avalanching as

838 observed at the NPLD (Russell et al., 2008), and winds could also strip away a

839 sublimation lag. The gradual fading of color contrast and weakening of ice spectral

840 signatures on one scarp over the course of a summer (Dundas et al., 2018) were

841 consistent with frost effects, as a lag might accumulate over the summer before being

842 removed by frost in the following winter and spring, and lineations suggesting frost-

843 driven mass wasting occur on scarps in early spring images (Fig. 16a). The latitudinal

844 dependence of scarp occurrence is consistent with a role for $\mathrm{CO}_{2}$ frost but would require

845 some additional control, since such frost is ubiquitous in the winter at middle and high

846 latitudes, and the abundance on the scarps is not known. Frost and wind effects are not

847 mutually exclusive. Ridge structures at some scarp locations (Fig. 16b) resemble features

848 interpreted as dust bedforms (Geissler, 2014) or indurated dust (Bridges et al., 2010)

849 elsewhere on Mars. These are oblique to the scarp and cut by it, suggesting limited

850 mobility relative to the scarp retreat timescale. For comparison, modeling of sublimation

851 conditions at migrating NPLD trough sites suggests that removal of a sublimation lag by

852 surface winds is likely necessary for sublimation to continue over prolonged periods there

853 (Bramson et al., 2019).

854 Cliffs on terrestrial debris-covered glaciers offer both insights and contrasts. Cliff

855 exposures can be created by sliding of the debris layer, or collapse into lakes or meltwater 
856 conduits (e.g., Kirkbride, 1993; Sakai et al., 2002). Neither of these is likely on Mars,

857 given the low slopes and lack of a significant meltwater system at Martian temperatures.

858 In the Himalayas on Earth, equator-facing slopes are quickly covered by debris, while

859 pole-facing ice cliffs persist and act as important drivers of ice loss, because they receive

860 less insolation and are steep enough to shed debris (Sakai et al., 2002; Buri and

861 Pellicciotti, 2018). Differences in the radiative balance of the upper and lower parts of the

862 slope as a function of aspect are important to the development of the cliffs: at some

863 aspects, melting and retreat of the lower slope is enhanced, helping to maintain a steep

864 exposure, while for others the reverse is true (Sakai et al., 2002). If such a dependency

865 exists for the relevant conditions on Mars, then for sufficiently clean ice, it could enable

866 steepening and runaway growth of a small exposure. A somewhat similar process is

867 observed in models of scalloped depressions, where small disturbances initially cause the

868 bottom of a depression to drop rapidly (Dundas et al., 2015). Antarctic analogs indicate

869 that calving of blocks via thermal expansion-induced cracking may be an important

870 driver of the retreat of steep scarps (e.g., Levy et al., 2013). This has not yet been

871 observed on Mars but is possible, and the scarp faces often appear fractured.

872 In a number of cases, scarps occur in the vicinity of other possible ice-loss

873 landforms and sometimes definitively within the same unit (e.g., Fig. 9). The relationship

874 between the scarp pits and scalloped depressions (e.g., Morgenstern et al., 2007; Soare et

875 al., 2008; Lefort et al., 2009; 2010; Zanetti et al., 2010) is not fully understood, but they

876 appear to form and evolve differently. The major evidence for this difference is that

877 linear ridges are observed parallel to some scarps (Fig. 8), indicating that the scarps

878 retreat in a straight line. Scalloped depressions, by contrast, have arcuate internal ridges 
879 (Lefort et al., 2009; Dundas, 2017a). The scarps typically widen as they retreat, resulting 880 in crudely triangular pits that are narrow on the poleward side and widest at the exposed 881 scarp, unlike scalloped depressions (Fig. 9c) and suggesting localized origination.

882 Additionally, the largest scarp pits are commonly multiple kilometers across and occur in 883 relative isolation, while scalloped depressions are typically smaller until mergers create

884 larger complex landforms. Scalloped depressions are commonly interpreted to be 885 sublimation-thermokarst that form via sublimation of an ice-rich unit much like that 886 revealed in the scarps (Morgenstern et al., 2007; Lefort et al., 2009; 2010; Zanetti et al., 887 2010; Dundas et al., 2015), so one possibility is that they represent different styles of 888 evolution relating to the occurrence of exposed surface ice versus loss through a lag.

889 Poorly defined expanded craters also occur near some scarps. These are interpreted as 890 sublimation-modified impact craters (Dundas et al., 2015; Viola et al., 2015), and the best

891 examples are in Milankovič crater (Fig. 9b). However, while the expanded craters there 892 appear in surface-mantling deposits similar to those hosting the scarps, they are generally

893 not adjacent: the expanded craters are mostly outside the rim of Milankovič, while the

894 scarps are in the crater interior. This could indicate a difference in material properties or 895 surface age, since most of the expanded craters in this region of Mars may be tens of 896 millions of years-old secondary craters (Viola et al., 2015), so the surface-mantling 897 deposits within the crater could be younger. Alternatively, this could indicate a role for 898 the effects of local slope or topography. Near the scarps, irregular pits are more common 899 than either scalloped depressions or expanded craters; given the setting and substrate, 900 these probably also represent ice-loss features. 
902 entirely distinct features, they may be best viewed as the result of different initial

903 conditions and evolutionary pathways for ice-rich deposits affected by sublimation, frost,

904 and wind. Hence, scallop-like landforms arise when disturbances destabilize the surface

905 and cause sublimation through a lag, and expanded craters are fundamentally similar but

906 result from relatively large initial disturbances (impacts) that are not completely erased

907 by sublimation as the crater expands. In cases of strong sublimation, expansion might

908 eventually make the original crater unrecognizable and transition to a scallop-like feature.

909 Both of these morphologies have been effectively modeled via lag-controlled sublimation

910 alone (Dundas et al., 2015; Dundas, 2017a) and retreat should concentrate on the

911 warmest, least-stable slopes. Exposed scarps fit within this framework if they represent a

912 different mode where wind, $\mathrm{CO}_{2}$ frost, or other factors maintain a bare ice surface which

913 retreats more quickly than ice that is covered by lithic debris, and thus occurs on the

914 slopes where those effects are strongest. The typically straight scarp morphology

915 represents a notable contrast from the other features. Individual landforms could change

916 modes: for instance, a scarp exposure might emerge within a scalloped depression if

917 erosion on the pole-facing slope removes lithic debris, and scarps could become buried if

918 the debris ceases to be removed effectively. The resulting morphologies could be

919 compound features dependent on the initial conditions and variations of the driving forces

920 over time, due both to climate variations and the changing shape of the landform itself.

921 This model raises two important questions. First, under what circumstances do these

922 processes produce well-defined scalloped depressions or expanded craters versus

923 irregular pits? And second, in regions of unstable or marginally stable ice, how much ice 
924 is lost to the atmosphere by this localized landform evolution, in comparison with

925 uniform sublimation?

926

927 5.4. Implications for Martian Climate and Ice Processes

928 The present-day distribution and properties of ice on Mars record the history of

929 climate, as they reflect an integrated history of deposition, internal processes (such as

930 densification and ice-lens formation), and sublimation. Ice that exists today is either

931 aggrading, stable, or was originally deposited in such abundance that subsequent periods

932 of instability have not been sufficient to remove it. The observations and interpretations

933 above provide some high-level insights about this history.

934 Atmospheric water vapor content is a major control on the distribution of stable

935 ice. If the ice-exposing craters are sampling the upper part of a thick massive ice body in

936 the Arcadia region as discussed above, then the elevated atmospheric water content

937 required to stabilize ice at the lowest-latitude craters (Dundas et al., 2014) might date to

938 the time of deposition or a time-integrated average over subsequent time rather than the

939 most recent climate, since thick ice units can survive over protracted periods while slowly

940 sublimating (e.g., Schorghofer and Forget, 2012; Bramson et al., 2017). If the ice was

941 deposited as snow, that water content would be a lower bound, since surface snow

942 deposition requires more water vapor than subsurface stability. However, the lag

943 developed during retreat must be thinner than predicted by Bramson et al. (2017)

944 assuming nominal conditions for the present day, or the shallow subsurface ice probed by

945 these craters contains excess ice above the deposit indicated by the radar reflectors.

946 Alternative histories for atmospheric water vapor might allow survival with a thinner lag, 
947 or sublimation lags may restrict sublimation more than observed in laboratory

948 experiments (Hudson et al., 2007). A generalized latitudinal model by Schorghofer and

949 Forget (2012) does allow lags < 1 meter over ice sheets with ages of a few million years

950 or less. The survival time of such ice sheets depends on both the climate history and the

951 time and amount of deposition, as well as the thermophysical properties of the lag itself.

952 As discussed above, scarps may indicate locations of particularly thick, clean ice

953 deposits originating as snow. The apparent high ice content at the scarps suggests that the

954 ratio of ice to dust in the atmosphere was high when deposition was occurring at those

955 locations. Scarps might not exist in all such deposits, and the specific ice bodies hosting

956 scarps may be influenced by local topography. Nevertheless, the scarps likely indicate a

957 subset of favored locations for past ice deposition. Several general circulation model

958 (GCM) studies have examined potential locations of past tropical or mid-latitude snow or

959 frost accumulation under different orbital configurations and axial tilt, with significant

960 differences in the details of model physics as well as in assumptions about $\mathrm{H}_{2} \mathrm{O}$ sources

961 and atmospheric dust abundance (e.g., Levrard et al., 2004; Forget et al, 2006; Madeleine

962 et al., 2009; 2014). Due to these differences and the limited sweep of parameter space

963 with any individual model, stating a simple hypothesis that could be tested by comparison

964 with the scarp distribution is not possible at present. Several scenarios do produce

965 concentrated ice accumulation south and southeast of the Hellas basin (hereafter SSE

966 Hellas), which has a marked influence on atmospheric circulation. These include

967 scenarios with low obliquity $\left(15-25^{\circ}\right)$ and an equatorial ice source, particularly with a

968 high optical depth of dust in the atmosphere (Levrard et al., 2004; Madeleine et al.,

969 2009), but also scenarios with $35^{\circ}$ obliquity and no equatorial ice source (Madeleine et 
970 al., 2014). The seasonal timing of perihelion also strongly affects deposition patterns

971 (Madeleine et al., 2009; 2014). Forget et al. (2006) produced strong deposition east of

972 Hellas, equatorward of the scarps, in a model scenario with $45^{\circ}$ obliquity and surface ice

973 at the south polar cap. Scenarios with both low and high obliquity can also produce

974 deposition in the region near Milankovič crater (Madeleine et al., 2009). Other locations

975 of predicted ice deposition in various scenarios do not correspond with scarps, although

976 some match the locations of debris-covered glaciers (e.g., Holt et al., 2008; Plaut et al.,

977 2009; Levy et al., 2014), scalloped depressions (e.g. Morgenstern et al., 2007; Lefort et

978 al., 2009; 2010; Zanetti et al., 2010), or expanded craters (e.g. Viola et al., 2015). The

979 evidence from the scarps favors the past occurrence of one or more of the climate

980 scenarios that produce strong deposition at the scarp locations, and the low dust content

981 of the scarp ice may favor those that produce accumulation with a low optical depth

982 atmosphere. However, Mars' orbital elements have varied widely (e.g., Laskar et al.,

983 2004) and the range of plausible parameters and assumptions makes it difficult to pick

984 out a specific scenario that is unambiguously recorded by the ice.

985 Well-defined meter-scale layering is found in only a few ice-exposing scarps, in

986 contrast with the NPLD where meter- to decameter-scale layering is nearly ubiquitous

987 (e.g., Herkenhoff et al., 2007). Unresolved layers ( $<30 \mathrm{~cm}$ thick) may exist at the mid-

988 latitude scarp sites, preserving a temporal record at small scales, but the more-common

989 crude layering may possibly be the only well-defined time signal in this ice, or the dust

990 content of the ice may be so low or so uniform that layers are mostly not distinguishable

991 in HiRISE images. This could indicate that the ice accumulated only under a narrow

992 range of atmospheric conditions, while polar accumulation occurred in a wider range of 
993 climates. However, surface-mantling deposits without ice exposures at latitudes $<45^{\circ}$ in

994 the mid-latitudes do show evidence of layering (Schon et al., 2009). The two scarp

995 locations with the clearest fine layering both have unconformities and crosscutting layers;

996 this may indicate that accumulation at those sites occurred at two different times possibly

997 with different climates or that some of the deposition occurred as windblown drifts rather

998 than uniform fall deposits. In both cases the uppermost material is approximately

999 horizontal and conforms to the present surface, so it was not affected significantly by

1000 aeolian transport or by ice flow, although deformation could be concentrated out of view 1001 at the base of the ice.

1002 The scarp ice likely records different climate episodes than either of the polar 1003 layered deposits. The available data are too limited to constrain any hypothesis for what 1004 orbital epochs and climate conditions might be recorded in the scarp ice other than to say 1005 that it indicates snow or frost accumulation. Part of this accumulation was likely 1006 geologically recent, since mid-latitude mantling deposits have few craters and young 1007 surface ages of a few million years (Schon et al., 2012), although the base of the deposits 1008 could be older. Harish et al. (2020) estimated the ages of two scarp-hosting craters to be 100925 and $95 \mathrm{Ma}$, and the surface age of one of the host mantling units to be $1 \mathrm{Ma}$. Viola et 1010 al. (2015) estimated that a mid-latitude icy deposit in the region of Milankovič crater is 1011 tens of millions of years old, and this may include the scarp-hosting ice there, although

1012 the characteristic expanded craters are less abundant in the crater interior, which could be 1013 a younger deposit (Fig. 9b). These ages are less than or comparable to the 30-100 Ma 1014 surface age of the SPLD (e.g., Koutnik et al., 2002), while the entire NPLD may date 1015 from the last several million years (e.g., Levrard et al., 2007; Byrne, 2009; Smith et al., 
1016 2016). More important than the specific age is that deposition in the poles and mid-

1017 latitudes likely occurred under different climate regimes: the locations of net deposition

1018 or loss depend on Mars' obliquity and orbital parameters and associated climate changes

1019 (e.g., Head et al., 2003; Levrard et al., 2004; Forget et al., 2006; Byrne, 2009; Madeleine

1020 et al., 2009; 2014), so polar and mid-latitude ice accumulated at different parts of the

1021 cycle.

1022 Overall, various observations indicate several regions of thick mid-latitude ice

1023 accumulation in the Late Amazonian. These include (1) SSE Hellas, as shown by scarps

1024 and scalloped depressions (Lefort et al., 2010; Zanetti et al., 2010); (2) western Utopia

1025 Planitia, as shown by scalloped depressions and radar reflectors (Morgenstern et al.,

1026 2007; Lefort et al., 2009; Stuurman et al., 2016); and (3) the greater Arcadia region, as

1027 shown by expanded craters and radar reflectors (Viola et al., 2015; Bramson et al., 2015)

1028 and some localized scarps. Debris-covered glaciers also indicate deposition concentrated

1029 east of Hellas, in Tempe Terra, and in the Deuteronilus and Protonilus Mensae regions

1030 (Holt et al., 2008; Plaut et al., 2009; Levy et al., 2014). Note that other major

1031 accumulations could have existed and been subsequently removed, as has occurred for

1032 some lobate debris aprons (Hauber et al., 2008). Deposition was probably not

1033 simultaneous in all of these regions, and the depositional conditions were also probably

1034 variable: ice in debris-covered glaciers and exposed in the scarps likely has a very low

1035 dust content (Campbell and Morgan, 2018; Dundas et al., 2018; Petersen et al., 2018), but

1036 the regional deposits in Utopia and Arcadia may be less ice-rich (Campbell and Morgan,

1037 2018). No site has all of the ice indicators in abundance. Radar reflectors are sparse in

1038 SSE Hellas, although rough topography limits the detectability of possible interfaces in 
1039 that region (Cook et al., 2020). Radar loss tangents support high ice contents for debris-

1040 covered glaciers but not for the Utopia and Arcadia deposits. Scarp exposures are sparse

1041 and not found at all in some regions. Additionally, one or the other of scalloped

1042 depressions and expanded craters dominate the sublimation-thermokarst population rather

1043 than a mix occurring. These differences could reflect differences in the lithic content of

1044 the ice (including layering), overburden properties, regional topography (influencing

1045 radar clutter) or the regional climate history.

\section{6. Conclusions}

1048 We present distributions of ice-exposing craters and large ice-exposing scarps at

1049 middle to high latitudes on Mars. Both types of feature indicate high subsurface ice

1050 contents well in excess of pore filling. Regional variations in the crater exposures suggest

1051 that high ice content is common at shallow depths at mid-latitudes $\left(\sim 40^{\circ} \mathrm{N}\right)$ in the

1052 Arcadia Planitia region compared with the northern part of the Tharsis rise, where pore

1053 ice may be more common. Above $\sim 50^{\circ}$ latitude, clean ice exposures are very common at

1054 all longitudes. The nature of ice exposures in some of the largest craters indicates that

1055 clean ice is not a product of the impact process. Variations in crater clusters demonstrate

1056 that both ice content and the depth to ice have substantial local variability. The scarps are

1057 characteristically found between $50-61^{\circ} \mathrm{N} / \mathrm{S}$ and are concentrated at particular

1058 longitudes. They appear to form in thick surface-mantling deposits produced by past

1059 snowfall and create a distinctive category of sublimation-thermokarst landform. The

1060 latitudinal and longitudinal controls suggest that the scarps form in locations with

1061 particularly thick, clean ice deposits and are exposed by a latitude-dependent process. 
1062 Both of these types of exposures provide important constraints on the climate history of 1063 Mars as well as reference locations for other remote-sensing data sets.

1065 Acknowledgments

1066 Icy scarp analysis was funded by the NASA Solar System Workings Program

1067 agreement 80HQTR19T0019, and assessment of HiRISE observations of ice-exposing

1068 craters was funded by the Mars Subsurface Water Ice Mapping project (JPL subcontract

1069 JPL1639821). SJC is grateful to the French Space Agency CNES for supporting her

1070 HiRISE-related work. IJD was funded by NASA Solar System Workings grant

1071 80NSSC20K0789. CTX, HiRISE, and CRISM targeting was funded by the Mars

1072 Reconnaissance Orbiter Project, and we thank the project operations teams for their work

1073 to acquire the data used in this study. The CTX operations team planned many images to

1074 search for new impacts and identified locations of candidates for HiRISE targeting. Jay

1075 Dickson and Mathieu Vincendon provided detailed and helpful reviews. Marc Hunter

1076 assisted with preparation of the USGS Data Release.

1077 The Supplementary Data is also available as a USGS Data Release at

1078 https://doi.org/10.5066/P9Y8FR1R (Dundas et al., 2021). All CTX, HiRISE, and CRISM

1079 image data used are available via the Planetary Data System Imaging and Geosciences

1080 nodes (https://pds-imaging.jpl.nasa.gov/volumes/mro.html and https://pds-

1081 geosciences.wustl.edu/missions/mro/crism.htm). All map-projected HiRISE images in

1082 figures are courtesy NASA/JPL/University of Arizona, and map-projected CTX images

1083 are courtesy NASA/JPL/MSSS/University of Arizona. Controlled THEMIS mosaics are

1084 publicly available (https://astrogeology.usgs.gov/maps/mars-themis-controlled-mosaics- 
1085 and-final-smithed-kernels) via Astropedia and uncontrolled mosaics are included as

1086 layers in JMARS (http://www.mars.asu.edu/data/), which was used for analysis. The

1087 original images used in the mosaics are available via the Planetary Data System Imaging

1088 Node (https://pds-imaging.jpl.nasa.gov/volumes/ody.html). Thermal Emission

1089 Spectrometer (TES) thermal inertia data are available from the PDS Geosciences node

1090 (https://pds-geosciences.wustl.edu/missions/mgs/tes-timap.html) and albedo data at the

1091 PDS TES data node (http://tes.asu.edu/products/index.html). The use of trade, product, or

1092 firm names is for identification purposes only and does not constitute an endorsement by

1093 the U.S. Government.

1094

1095 References

1096 Appéré, T., Schmitt, B., Langevin, Y., Douté, S., Pommerol, A., Forget, F., Spiga, A.,

1097 Gondet, B., Bibring, J.-P. (2011). Winter and spring evolution of northern seasonal

1098 deposits on Mars from OMEGA on Mars Express. J. Geophys. Res., 115, E05001.

1099 https://doi.org/10.1029/2010JE003762.

1100 Aylward, D. S., Schmidt, L. M., Levy, J. S. (2019). Formation of coarse sediment lags in

1101 ice-sediment mixtures: A geomorphic signature of sublimation on regolith surfaces.

1102 Planet. Space Sci., 174, 8-13. https://doi/org/10.1016/j.pss.2019.05.006.

1103 Bandfield, J. L. (2007). High-resolution subsurface water-ice distributions on Mars.

$1104 \quad$ Nature, 447, 64-67. https://doi.org/10.1038/nature05781.

1105 Bandfield, J. L., \& Feldman, W. C. (2008). Martian high-latitude permafrost depth and

1106 surface cover thermal inertia distributions. J. Geophys. Res., 113, E08001.

$1107 \quad$ https://doi.org/10.1029/2007JE003007. 
1108 Bart, G. D. (2014). The quantitative relationship between small impact crater morphology

1109 and regolith depth. Icarus, 235, 130-135.

$1110 \quad$ https://doi.org/10.1016/j.icarus.2014.03.020.

1111 Boynton, W. V., Feldman, W. C., Squyres, S. W., Prettyman, T. H., Brückner, J., Evans,

1112 L. G., et al. (2002). Distribution of hydrogen in the near surface of Mars: Evidence

1113 for subsurface ice deposits. Science, 297, 81-85.

$1114 \quad$ https://doi.org/10.1126/science.1073722.

1115 Bramson, A. M., Byrne, S., Putzig, N. E., Sutton, S., Plaut, J. J., Brothers, T. C., \& Holt,

1116 J. W. (2015). Widespread excess ice in Arcadia Planitia, Mars. Geophys. Res. Lett.,

1117 42, 6566-6574. https://doi.org/10.1002/2015GL064844.

1118 Bramson, A. M., Byrne, S., Bapst, J. (2017). Preservation of mid-latitude ice sheets on

1119 Mars. J. Geophys. Res., 122, 2,250-2,266. https://doi.org/10.1002/2017JE005357.

1120 Bramson, A. M., Byrne, S., Bapst, J., Smith, I. B., McClintock, T. (2019). A migration

1121 model for the polar spiral troughs of Mars. J. Geophys. Res., 124, 1,020-1,043.

1122 https://doi.org/10.1029/2018JE005806.

1123 Bridges, N. T., et al. (2010). Aeolian bedforms, yardangs, and indurated surfaces in the

1124 Tharsis Montes as seen by the HiRISE camera: Evidence for dust aggregates. Icarus,

$1125 \quad$ 205, 165-182. https://doi.org/10.1016/j.icarus.2009.05.017.

1126 Buri, P., Pellicciotti, F. (2018). Aspect controls the survival of ice cliffs on debris-

1127 covered glaciers. Proc. Nat. Acad. Sci., 115, 4,369-4,374.

$1128 \quad$ https://doi.org/10.1073/pnas.1713892115.

1129 Byrne, S. (2009). The polar deposits of Mars. Ann. Rev. Earth Planet. Sci., 37, 535-560.

1130 https://doi.org/10.1146/annurev.earth.031208.100101. 
1131 Byrne, S., Dundas, C. M., Kennedy, M. R., Mellon, M. T., McEwen, A. S., Cull, S. C., et

1132 al. (2009). Distribution of mid-latitude ground ice on Mars from new impact craters.

1133 Science, 325, 1674-1676. https://doi.org/10.1126/science.1175307.

1134 Campbell, B. A., Morgan, G. A. (2018). Fine-scale layering of Mars polar deposits and

1135 signatures of ice content in nonpolar material from multiband SHARAD data

1136 processing. Geophys. Res. Lett., 45, 1,759-1,766.

1137 https://doi.org/10.1002/2017GL075844.

1138 Chamberlain, M. A., \& Boynton, W. V. (2007). Response of Martian ground ice to orbit-

1139 induced climate change. J. Geophys. Res., 112, E06009.

$1140 \quad$ https://doi.org/10.1029/2006JE002801.

1141 Christensen, P. R., Bandfield, J. L., Hamilton, V. E., Ruff, S. W., Kieffer, H. H., et al.

1142 (2001). Mars Global Surveyor Thermal Emission Spectrometer experiment:

1143 Investigation description and surface science results. J. Geophys. Res., 106, 23,823-

$1144 \quad 23,871$. https://doi.org/10.1029/2000JE001370.

1145 Christensen, P. R., Jakosky, B. M., Kieffer, H. H., Malin, M. C., McSween, H. Y. Jr.,

1146 Nealson, K., et al. (2004). The Thermal Emission Imaging System (THEMIS) for the

1147 Mars 2001 Odyssey mission. Space Sci. Rev., 110(1), 85-130.

$1148 \quad$ https://doi.org/10.1023/B:SPAC.0000021008.16305.94.

1149 Clark, R. N., \& Lucey, P. G. (1984). Spectral properties of ice-particulate mixtures and

1150 implications for remote sensing. 1. Intimate mixtures. J. Geophys. Res., 89, 6,341-

$1151 \quad 6,348$. https://doi.org/10.1029/JB089iB07p06341.

1152 Conway, S. J., \& Balme, M. R. (2014). Decameter thick remnant glacial ice deposits on 1153 Mars. Geophys. Res. Lett., 41, 5402-5409. https://doi.org/10.1002/2014GL060314. 
1154 Cook, C. W., Bramson, A. M., Byrne, S., Holt, J. W., Christoffersen, M. S., Viola, D.,

1155 Dundas, C. M., Goudge, T. A. (2020). Sparse subsurface radar reflectors in Hellas

1156 Planitia, Mars. Icarus, 348, article \#113847.

$1157 \quad$ https://doi.org/10.1016/j.icarus.2020.113847.

1158 Cull, S., Arvidson, R. E., Mellon, M. T., Skemer, P., Shaw, A., Morris, R. V. (2010).

1159 Composition of subsurface ices at the Mars Phoenix landing site. Geophys. Res. Lett.,

1160 37, L24203. https://doi.org/10.1029/2010GL045372.

1161 Delamere, W. A., et al. (2010). Color imaging of Mars by the High Resolution Imaging

1162 Science Experiment (HiRISE). Icarus, 205, 38-52.

1163 https://doi.org/10.1016/j.icarus.2009.03.012.

1164 Dundas, C. M. (2017a). Effects of varying obliquity on Martian sublimation thermokarst

1165 landforms. Icarus, 281, 115-120. https://doi.org/10.1016/j.icarus.2016.08.031.

1166 Dundas, C. M. (2017b). Effects of lava heating on volatile-rich slopes on Io. J. Geophys.

1167 Res. Planets, 122, 546-559. https://doi.org/10.1002/2016JE005177.

1168 Dundas, C. M., Byrne, S., McEwen, A. S., Mellon, M. T., Kennedy, M. R., Daubar, I. J.,

1169 Saper, L. (2014). HiRISE observations of new impact craters exposing Martian

1170 ground ice. J. Geophys. Res., 119, 109-127. https://doi.org/10.1002/2013JE004482.

1171 Dundas, C. M., Byrne, S., \& McEwen, A. S. (2015). Modeling the development of

1172 Martian sublimation thermokarst landforms. Icarus, 262, 154-169.

$1173 \quad$ https://doi.org/10.1016/j.icarus.2015.07.033.

1174 Dundas, C. M., Bramson, A. M., Ojha, L., Wray, J. J., Mellon, M. T., Byrne, S., et al.

1175 (2018). Exposed subsurface ice sheets in the Martian mid-latitudes. Science, 359,

1176 199-201. https://doi.org/10.1126/science.aao1619. 
1177 Dundas, C. M., McEwen, A. S., Diniega, S., Hansen, C. J., Byrne, S., McElwaine, J. N.

1178 (2019). The formation of gullies on Mars today. Geol. Soc. London Spec. Pub., 467,

1179 67-94. https://doi.org/10.1144/SP467.5.

1180 Dundas, C. M., Mellon, M. T., Conway, S. J., Daubar, I. J., Williams, K. E., Ojha, L.,

1181 Wray, J. J., Bramson, A. M., Byrne, S., McEwen, A. S., Posiolova, L. V., Speth, G.,

1182 Viola, D., Landis, M., Morgan, G. A., and Pathare, A. V. (2021). Supplementary Data

1183 for "Widespread Exposures of Extensive Clean Shallow Ice in the Mid-Latitudes of

1184 Mars": U.S. Geological Survey data release. https://doi.org/10.5066/P9Y8FR1R.

1185 Fassett, C. I., Levy, J. S., Dickson, J. L., \& Head, J. W. (2014). An extended period of

1186 episodic northern mid-latitude glaciation on Mars during the Middle to Late

1187 Amazonian: Implications for long-term obliquity history. Geology, 42, 763-766.

1188 https://doi.org/10.1130/G35798.1.

1189 Fergason, R. L., \& Weller, L. (2019). The THEMIS controlled mosaics of Mars and final $1190 \quad$ smithed kernels. $4^{\text {th }}$ Planetary Data Workshop, abstract \#7059.

1191 Fischer, E. M., \& Pieters, C. M. (1993). The continuum slope of Mars: Bidirectional

1192 reflectance investigations and applications to Olympus Mons. Icarus, 102, 185-202.

1193 https://doi.org/10.1006/icar.1993.1043.

1194 Fisher, D. A. (2005). A process to make massive ice in the Martian regolith using long-

1195 term diffusion and thermal cracking. Icarus, 179, 387-397.

1196 https://doi.org/10.1016/j.icarus.2005.07.024.

1197 Forget, F., Haberle, R. M., Montmessin, F., Levrard, B., Head, J. W. (2006). Formation

1198 of glaciers on Mars by atmospheric precipitation at high obliquity. Science, 311, 368-

1199 371. https://doi.org/10.1126/science.1120335. 
1200 Geissler, P. E. (2014). The birth and death of transverse aeolian ridges on Mars. J.

1201 Geophys. Res., 119, 2583-2599. https://doi.org/10.1002.2014JE004633.

1202 Haltigin, T., Osinski, G., Baylis, A., Barnard, I. (2018). Orbital Synthetic Aperture Radar

1203 for subsurface ice detection on Mars: Scientific rationale and Canadian technical

$1204 \quad$ concept. $42^{\text {nd }}$ COSPAR Scientific Assembly, abstract B4.2-33-18.

1205 Harish, Vijayan, S., Mangold, N., Bhardwaj, A. (2020). Water-ice exposing scarps within

1206 the northern mid-latitude craters on Mars. Geophys. Res. Lett., 47, e2020GL089057.

1207 https://doi.org/10.1029/2020GL089057.

1208 Hauber, E., van Gasselt, S., Chapman, M. G., Neukum, G. (2008). Geomorphic evidence

1209 for former lobate debris aprons at low latitudes on Mars: Indicators of the Martian

1210 paleoclimate. J. Geophys. Res., 113, E02007. https://doi.org/10.1029/2007JE002897.

1211 Head, J. W., Mustard, J. F., Kreslavsky, M. A., Milliken, R. E., Marchant, D. R. (2003).

1212 Recent ice ages on Mars. Nature, 426, 797-802. https://doi.org/10.1038/nature02114.

1213 Heldmann, J. L., Schurmeier, L., McKay, C., Davila, A., Stoker, C., Marinova, M.,

1214 Wilhelm, M. B. (2014). Midlatitude ice-rich ground on Mars as a target in the search

1215 for evidence of life and for in situ resource utilization on human missions.

1216 Astrobiology, 14, 102-118. https://doi.org/10.1089/ast.2013.1103.

1217 Herkenhoff, K. E., Byrne, S., Russell, P. S., Fishbaugh, K. E., \& McEwen, A. S. (2007).

1218 Meter-scale morphology of the north polar region of Mars. Science, 317, 1711-1715.

$1219 \quad$ https://doi.org/10.1126/science.1143544.

1220 Holt, J. W., et al. (2008). Radar sounding evidence for buried glaciers in the southern

1221 mid-latitudes of Mars. Science, 322, 1,235-1,238.

1222 https://doi.org/10.1126/science.1164246. 
1223 Hudson, T. L., Aharonson, O., Schorghofer, N., Farmer, C. B., Hecht, M. H., Bridges, N.

1224 T. (2007). Water vapor diffusion in Mars subsurface environments. J. Geophys. Res.,

1225 112, E05016. https://doi.org/10.1029/2006JE002815.

1226 Hudson, T. L., Aharonson, O. (2008). Diffusion barriers at Mars surface conditions: Salt

1227 crusts, particle size mixtures, and dust. J. Geophys. Res., 113, E09008.

1228 https://doi.org/10.1029/2007JE003026.

1229 Kerrigan, M. (2013). The periglacial landscape of Utopia Planitia: Geologic evidence for

1230 recent climate change on Mars. MS thesis, Dept. of Earth Sciences, Univ. Western

1231 Ontario, London, Ontario, Canada.

1232 Khuller, A. R., \& Christensen, P. R. (2019). Evidence of water-rich snow deposits within

1233 Martian gullies. Lunar Planet. Sci. Conf. 50, abstract \#3060.

1234 Kieffer, H. H. (2007). Cold jets in the Martian polar caps. J. Geophys. Res., 112, E08005.

$1235 \quad$ https://doi.org/10.1029/2006JE002816.

1236 Kirkbride, M. P. (1993). The temporal significance of transitions from melting to calving

1237 termini at glaciers in the central Southern Alps of New Zealand. The Holocene, 3,

1238 232-240. https://doi.org/10.1177/095968369300300305.

1239 Koutnik, M., Byrne, S., Murray, B. (2002). J. Geophys. Res. Planets, 107, E11, 5100.

$1240 \quad$ https://doi.org/10.1029/2001JE001805.

1241 Landis, M., McEwen, A. S., Daubar, I. J., Hayne, P. O., Byrne, S., Dundas, C. M.,

1242 Sutton, S. S., Britton, A., Herkenhoff, K. E. (2020). South Polar Layered Deposits

1243 near-surface properties inferred from a dated impact crater. $7^{\text {th }}$ Int. Conf. Mars Polar

1244 Sci. Expl., abstract \#6025. 
1245 Laskar, J., Correia, A. C. M., Gastineau, M., Joutel, F., \& Levrard, B. (2004). Long term

1246 evolution and chaotic diffusion of the insolation quantities of Mars. Icarus, 170, 343-

1247 364. https://doi.org/10.1016/j.icarus.2004.04.005.

1248 Lefort, A., Russell, P. S., Thomas, N., McEwen, A. S., Dundas, C. M., \& Kirk, R. L.

1249 (2009). Observations of periglacial landforms in Utopia Planitia with the High

1250 Resolution Imaging Science Experiment (HiRISE). J. Geophys. Res., 114, E04005.

1251 https://doi.org/10.1029/2008JE003264.

1252 Lefort, A., Russell, P. S., \& Thomas, N. (2010). Scalloped terrains in the Peneus and

1253 Amphitrites Paterae region of Mars as observed by HiRISE. Icarus, 205, 259-268.

$1254 \quad$ https://doi.org/10.1016/j.icarus.2009.06.005.

1255 Leighton, R. B., \& Murray, B. C. (1966). Behavior of carbon dioxide and other volatiles

1256 on Mars. Science, 153, 136-144. https://doi.org/10.1126/science.153.3732.136.

1257 Levrard, B., Forget, F., Montmessin, F., Laskar, J. (2004). Recent ice-rich deposits

1258 formed at high latitudes on Mars by sublimation of unstable equatorial ice during low

1259 obliquity. Nature, 431, 1,072-1,075. https://doi.org/10.1038/nature03055.

1260 Levrard, B., Forget, F., Montmessin, F., Laskar, J. (2007). Recent formation and

1261 evolution of northern Martian polar layered deposits as inferred from a global climate

1262 model. J. Geophys. Res., 112, E06012. https://doi.org/10.1029/2006JE002772.

1263 Levy, J. S., Head, J., Marchant, D. (2009a). Thermal contraction crack polygons on Mars:

1264 Classification, distribution, and climate implications from HiRISE observations. $J$.

1265 Geophys. Res., 114, E01007. https://doi.org/10.1029/2008JE003273. 
1266 Levy, J. S., Head, J., Marchant, D. (2009b). Concentric crater fill in Utopia Planitia:

1267 History and interaction between glacial "brain terrain" and periglacial mantle

1268 processes. Icarus, 202, 462-476. https://doi.org/10.1016/j.icarus.2009.02.018.

1269 Levy, J. S., Fountain, A. G., Dickson, J. L., Head, J. W., Okal, M., Marchant, D. R.,

1270 Watters, J. (2013). Accelerated thermokarst formation in the McMurdo Dry Valleys,

1271 Antarctica. Sci. Rep., 3, 2269. https://doi.org/10.1038/srep02269.

1272 Levy, J. S., Fassett, C. I., Head, J. W., Schwartz, C., Watters, J. L. (2014). Sequestered

1273 ice contribution to the global Martian water budget: Geometric constraints on the

1274 volume of remnant, midlatitude debris-covered glaciers. J. Geophys. Res., 119, 2,188-

1275 2,196. https://doi.org/10.1002/2014JE004685.

1276 Madeleine, J.-B., Forget, F., Head, J. W., Levrard, B., Montmessin, F., Millour, E.

1277 (2009). Amazonian northern mid-latitude glaciation on Mars: A proposed climate

1278 scenario. Icarus, 203, 390-405. https://doi.org/10.1016/j.icarus.2009.04.037.

1279 Madeleine, J.-B., Head, J. W., Forget, F., Navarro, T., Millour, E., Spiga, A., Colaïtis, A.,

1280 Määttänen, A., Montmessin, F., \& Dickson, J. L. (2014). Recent Ice Ages on Mars:

1281 The role of radiatively active clouds and cloud microphysics. Geophys. Res. Lett., 41,

1282 4873-4879. https://doi.org/10.1002/2014GL059861.

1283 Malin, M. C., Bell, J. F., Cantor, B. A., Caplinger, M. A., Calvin, W. M., et al. (2007).

1284 Context Camera investigation on board the Mars Reconnaissance Orbiter. J. Geophys.

1285 Res., 112, E05S04. https://doi.org/10.1029/2006JE002808.

1286 Mangold, N. (2005). High latitude patterned grounds on Mars: Classification, distribution

1287 and climatic control. Icarus, 174, 336-359.

1288 https://doi.org/10.1016/j.icarus.2004.07.030. 
1289 McEwen, A. S., Eliason, E. M., Bergstrom, J. W., Bridges, N. T., Hansen, C. J., et al.

1290 (2007). Mars Reconnaissance Orbiter's High Resolution Imaging Science

1291 Experiment. J. Geophys. Res., 112, E05S02. https://doi.org/10.1029/2005JE002605.

1292 Mellon, M. T. (1997). Small-scale polygonal features on Mars: Seasonal thermal

1293 contraction cracks in permafrost. J. Geophys. Res., 102, 25,617-25,628.

$1294 \quad$ https://doi.org/10.1029/97JE02582.

1295 Mellon, M. T., \& Jakosky, B. M. (1993). Geographic variations in the thermal and

1296 diffusive stability of ground ice on Mars. J. Geophys. Res., 98, 3345-3364.

$1297 \quad$ https://doi.org/10.1029/92JE02355.

1298 Mellon, M. T., \& Jakosky, B. M. (1995). The distribution and behavior of Martian

1299 ground ice during past and present epochs. J. Geophys. Res., 100, 11,781-11,799.

$1300 \quad$ https://doi.org/10.1029/95JE01027.

1301 Mellon, M. T., Feldman, W. C., \& Prettyman, T. H. (2004). The presence and stability of

1302 ground ice in the southern hemisphere of Mars. Icarus, 169, 324-340.

$1303 \quad$ https://doi.org/10.1016/j.icarus.2003.10.022.

1304 Mellon, M. T., Arvidson, R. E., Sizemore, H. G., Searls, M. L., Blaney, D. L., Cull, S., et 1305 al. (2009). Ground ice at the Phoenix landing site: Stability state and origin. $J$.

1306 Geophys. Res., 114, E00E07. https://doi.org/10.1029/2009JE003417.

1307 Melosh, H. J. (1989). Impact Cratering: A Geologic Process. New York: Oxford $1308 \quad$ University Press.

1309 MEPAG ICE-SAG Report (2019). Report from the Ice and Climate Evolution Science 1310 Analysis Group (ICE-SAG). S. Diniega and N. E. Putzig (chairs), 157 pages posted 8 
1311 July 2019 by the Mars Exploration Program Analysis Group (MEPAG) at 1312 http://mepag.nasa.gov/reports.cfm.

1313 Milliken, R. A., Mustard, J. F., \& Goldsby, D. L. (2003). Viscous flow features on the 1314 surface of Mars: Observations from high-resolution Mars Orbiter Camera (MOC) 1315 images. J. Geophys. Res., 108, 5057. https://doi.org/10.1029/2002JE002005.

1316 Mitrofanov, I. G., Malakhov, A. V., Golovin, D. V., Litvak, M. L., Sanin, A. B., 1317 Mokrousov, M. I. (2018). Neutron mapping of Mars with high spatial resolution: First 1318 results of the FREND experiment of the ExoMars project. Proceedings of the Russian 1319 Academy of Science, the Branch of Physical Science.

1320 Morgan, G. A., et al. (2020). Subsurface water ice mapping (SWIM) on Mars: Radar 1321 surface reflectivity. Lunar Planet. Sci. Conf. 51, abstract \#2790.

1322 Morgenstern, A., Hauber, E., Reiss, D., van Gasselt, S., Grosse, G., Schirrmeister, L. 1323 (2007). Deposition and degradation of a volatile-rich later in Utopia Planitia and 1324 implications for climate history on Mars. J. Geophys. Res., 112, E06010.

1325 https://doi.org/10.1029/2006JE002869.

1326 Mouginot, J., Pommerol, A., Kofman, W., Beck, P., Schmitt, B., Herique, A., Grima, C., 1327 Safaeinili, A., \& Plaut, J. J. (2010). The 3-5 MHz global reflectivity map of Mars by 1328 MARSIS/Mars Express: Implications for the current inventory of subsurface $\mathrm{H}_{2} \mathrm{O}$. 1329 Icarus, 210, 612-625. https://doi.org/10.1016/j.icarus.2010.07.003.

1330 Murray, B. C., Ward, W. R., \& Yeung, S. C. (1973). Periodic insolation variations on 1331 Mars. Science, 180, 638-640. https://doi.org/10.1126/science.180.4086.638. 
1332 Mustard, J. F., Cooper, C. D., Rifkin, M. K. (2001). Evidence for recent climate change

1333 on Mars from the identification of youthful near-surface ground ice. Nature, 412,

1334 411-414. https://doi.org/10.1038/35086515.

1335 Noe Dobrea, E. Z., Asphaug, E., Grant, J. A., Kessler, M. A., Mellon, M. T. (2007).

1336 Patterned ground as an alternative explanation for the formation of brain coral

1337 textures in the mid latitudes of Mars: HiRISE observations of lineated valley fill

1338 textures. $7^{\text {th }}$ Int. Conf. Mars, abstract \#3358.

1339 Orloff, T. C., Kreslavsky, M. A., Asphaug, E. I. (2013). Possible mechanism of boulder

$1340 \quad$ clustering on Mars. Icarus, 225, 992-999.

1341 https://doi.org/10.1016/j.icarus.2013.01.002.

1342 Pathare, A. V., Feldman, W. C., Prettyman, T. H., \& Maurice, S. (2018). Driven by

1343 excess? Climatic implications of new global mapping of near-surface water-

1344 equivalent hydrogen on Mars. Icarus, 301, 97-116.

$1345 \quad$ https://doi.org/10.1016/j.icarus.2017.09.031.

1346 Petersen, E. I., Holt, J. W., \& Levy, J. S. (2018). High ice purity of Martian lobate debris

1347 aprons at the regional scale: Evidence from an orbital radar sounding survey in

1348 Deuteronilus and Protonilus Mensae. Geophys. Res. Lett., 45, 11,595-11,604.

$1349 \quad$ https://doi.org/10.1029/2018GL079759.

1350 Picardi, G., et al. (2005). Radar soundings of the subsurface of Mars. Science, 310, 1,925-

$1351 \quad$ 1,928. https://doi.org/10.1126/science.1122165.

1352 Pilorget, C., \& Forget, F. (2016). Formation of gullies on Mars by debris flows triggered

1353 by $\mathrm{CO}_{2}$ sublimation. Nature Geosci., 9, 65-69. https://doi.org/10.1038/NGEO2619. 
1354 Piqueux, S., Buz, J., Edwards, C. S., Bandfield, J. L., Kleinböhl, A., Kass, D. M., Hayne, 1355 P. O., \& the MCS and THEMIS teams (2019). Widespread shallow water ice on Mars 1356 at high latitudes and mid latitudes. Geophys. Res. Lett., 46, 14,290-14,298.

1357 https://doi.org/10.1029/2019GL083947.

1358 Plaut, J. J., et al. (2007). Subsurface radar sounding of the south polar layered deposits of 1359 Mars. Science, 316, 92-95. https://doi.org/10.1126/science.1139672.

1360 Plaut, J. J., Safaeinili, A., Holt, J. W., Phillips, R. J., Head, J. W., Seu, R., Putzig, N. E., 1361 \& Frigeri, A. (2009). Radar evidence for ice in lobate debris aprons in the mid1362 northern latitudes of Mars. Geophys. Res. Lett., 36, L02203. 1363 https://doi.org/10.1029/2008GL036379.

1364 Putzig, N. E., \& Mellon, M. T. (2007). Apparent thermal inertia and the surface 1365 heterogeneity of Mars. Icarus, 191, 68-94.

1366 https://doi.org/10.1016/j.icarus.2007.05.013.

1367 Putzig, N. E., et al. (2019). Results of the Mars Subsurface Water Ice Mapping (SWIM) 1368 project. $9^{\text {th }}$ Int. Mars Conference, abstract \#6427.

1369 Putzig, N. E., et al. (2020). Subsurface Water Ice Mapping (SWIM) on Mars to support in 1370 situ resource utilization. Lunar and Planetary Science Conference 51, abstract \#2648.

1371 Quaide, W. L., Oberbeck, V. R. (1968). Thickness determination of the lunar surface 1372 layer from lunar impact craters. J. Geophys. Res., 73, 5,247-5,270.

$1373 \quad$ https://doi.org/10.1029/JB073i016p05247.

1374 Reufer, A., Thomas, N., Benz, W., Byrne, S., Bray, V., Dundas, C., \& Searls, M. (2010). 1375 Models of high velocity impacts into dust-covered ice: Application to Martian 
northern lowlands. Planet. Space Sci., 58, 1160-1168.

$1377 \quad$ https://doi.org/10.1016/j.pss.2010.04.008.

1378 Rice, M. S., Bell, J. F., Cloutis, E. A., Wray, J. J., Herkenhoff, K. E., Sullivan, R.,

1379 Johnson, J. R., \& Anderson, R. B. (2011). Temporal observations of bright soil

1380 exposures at Gusev crater, Mars. J. Geophys. Res., 116, E00F14.

$1381 \quad$ https://doi.org/10.1029/2010JE003683.

1382 Ruff, S. W., \& Christensen, P. R. (2002). Bright and dark regions on Mars: Particle size

1383 and mineralogical characteristics based on Thermal Emission Spectrometer data. $J$.

1384 Geophys. Res., 107, E12, 5127. https://doi.org/10.1029/2001JE001580.

1385 Russell, P., et al. (2008). Seasonally active frost-dust avalanches on a north polar scarp of

1386 Mars captured by HiRISE. Geophys. Res. Lett., 35, L23204.

$1387 \quad$ https://doi.org/10.1029/2008GL035790.

1388 Sakai, A., Nakawo, M., Fujita, K. (2002). Distribution characteristics and energy balance

1389 of ice cliffs on debris-covered glaciers, Nepal Himalaya. Arctic, Antarctic and Alpine

1390 Research, 34, 12-19. https://doi.org/10.1080/15230430.2002.12003463.

1391 Schon, S. C., Head, J. W., Milliken, R. E. (2009). A recent ice age on Mars: Evidence for

1392 climate oscillations from regional layering in mid-latitude mantling deposits.

1393 Geophys. Res. Lett., 36, L15202. https://doi.org/10.1029/2009GL038554.

1394 Schon, S. C., Head, J. W., Fassett, C. I. (2012). Recent high-latitude resurfacing by a

1395 climate-related latitude-dependent mantle: Constraining age of emplacement from

1396 counts of small craters. Planet. Space Sci., 69, 49-61.

1397 https://doi.org/10.1016/j.pss.2012.03.015. 
1398 Schorghofer, N., \& Aharonson, O. (2005). Stability and exchange of subsurface ice on

1399 Mars. J. Geophys. Res., 110, E05003. https://doi.org/10.1029/2004JE002350.

1400 Schorghofer, N., \& Forget, F. (2012). History and anatomy of subsurface ice on Mars.

1401 Icarus, 220, 1112-1120. https://doi.org/10.1016/j.icarus.2012.07.003.

1402 Sizemore, H. G., \& Mellon, M. T. (2006). Effects of soil heterogeneity on Martian

1403 ground-ice stability and orbital estimates of ice table depth. Icarus, 185, 358-369.

$1404 \quad$ https://doi.org/10.1016/j.icarus.2006.07.018.

1405 Sizemore, H. G., Zent, A. P., \& Rempel, A. W. (2015). Initiation and growth of Martian

1406 ice lenses. Icarus, 251, 191-210. https://doi.org/10.1016/j.icarus.2014.04.013.

1407 Smith, I. B., Putzig, N. E., Holt, J. W., Phillips, R. J. (2016). An ice age recorded in the

1408 polar deposits of Mars. Science, 352, 1075-1079.

$1409 \quad$ https://doi.org/10.1126/science.aad6968.

1410 Smith, I. B., Diniega, S., Beaty, D. W., Thorsteinsson, T., Becerra, P., Bramson, A. M., et

1411 al. (2018). $6^{\text {th }}$ International Conference on Mars Polar Science and Exploration:

1412 Conference summary and five top questions. Icarus, 308, 2-14.

$1413 \quad$ https://doi.org/10.1016/j.icarus.2017.06.027.

1414 Smith, P. H., Tamppari, L. K., Arvidson, R. E., Bass, D., Blaney, D., Boynton, W. V., et

1415 al. (2009). $\mathrm{H}_{2} \mathrm{O}$ at the Phoenix landing site. Science, 325, 58-61.

$1416 \quad$ https://doi.org/10.1126/science.1172339.

1417 Soare, R. J., Osinski, G. R., Roehm, C. L. (2008). Thermokarst lakes and ponds on Mars

1418 in the very recent (Late Amazonian) past. Earth Planet. Sci. Lett., 272, 382-393.

$1419 \quad$ https://doi.org/10.1016/j.eps1.2008.05.010. 
1420 Soderblom, L. A., Kreidler, T. J., Masursky, H. (1973). Latitudinal distribution of a

1421 debris mantle on the Martian surface. J. Geophys. Res., 78, 4,117-4,122.

1422 https://doi.org/10.1029/JB078i020p04117.

1423 Squyres, S. W. (1978). Martian fretted terrain: Flow of erosional debris. Icarus, 34, 600-

1424 613. https://doi.org/10.1016/0019-5(78)90048-9.

1425 Squyres, S. W., Carr, M. H. (1986). Geomorphic evidence for the distribution of ground

1426 ice on Mars. Science, 231, 249-252. https://doi.org/10.1126/science.231.4735.249.

1427 Steele, L. J., Balme, M. R., \& Lewis, S. R. (2017). Regolith-atmosphere exchange of

1428 water in Mars' recent past. Icarus, 284, 233-248.

1429 https://doi.org/10.1016/j.icarus.2016.11.023.

1430 Stuurman, C. M., Osinski, G. R., Holt, J. W., Levy, J. S., Brothers, T. C., Kerrigan, M., \&

1431 Campbell, B. A. (2016). SHARAD detection and characterization of subsurface water

1432 ice deposits in Utopia Planitia, Mars. Geophys. Res. Lett., 43, 9484-9491,

$1433 \quad$ https://doi.org/10.1002/2016GL070138.

1434 van Everdingen, R. O., ed. (1998, revised 2005). Multi-language glossary of permafrost

1435 and related ground-ice terms. International Permafrost Association, 159 pages.

1436 Vincendon, M., Forget, F., Mustard, J. (2010). Water ice at low to midlatitudes on Mars.

$1437 \quad J$. Geophys. Res., 115, E10001. https://doi.org/10.1029/2010JE003584.

1438 Viola, D., McEwen, A. S. (2018). Geomorphological evidence for shallow ice in the

1439 southern hemisphere of Mars. Geophys. Res. Lett, 123, 262-277.

$1440 \quad$ https://doi.org/10.1002/2017JE005366. 
1441 Viola, D., McEwen, A. S., Dundas, C. M., \& Byrne, S. (2015). Expanded secondary

1442 craters in the Arcadia Planitia region, Mars: Evidence for tens of Myr-old shallow

1443 subsurface ice. Icarus, 248, 190-204. https://doi.org/10.1016/j.icarus.2014.10.032.

1444 Ward, W. R. (1973). Large-scale variations in the obliquity of Mars. Science, 181, 260-

$1445 \quad 262$. https://doi.org/10.1126/science.181.4096.260.

1446 Wells, E. N., Veverka, J., \& Thomas, P. (1984). Mars: Experimental study of albedo

1447 changes caused by dust fallout. Icarus, 58, 331-338. https://doi.org/10.1016/0019-

$1448 \quad \underline{1035(84) 90079-4 .}$

1449 Zanetti, M., Hiesinger, H., Reiss, D., Hauber, E., \& Neukum, G. (2010). Distribution and

1450 evolution of scalloped terrain in the southern hemisphere, Mars. Icarus, 206, 691-706.

$1451 \quad$ https://doi.org/10.1016/j.icarus.2009.09.010.

1452 Zuber, M. T., Phillips, R. J., Andrews-Hanna, J. C., Asmar, S. W., Konopliv, A. S.,

1453 Lemoine, F. G., Plaut, J. J., Smith, D. E., \& Smrekar, S. E. (2007). Density of Mars'

1454 south polar layered deposits. Science, 317, 1718-1719.

$1455 \quad$ https://doi.org/10.1126/science.1146995.

1456 
1457 Table 1. Depths to Strong Layer at Impact Sites with Icy Color

\begin{tabular}{|l|l|l|l|l|}
\hline Latitude & Longitude & $\mathrm{N}$ & $\begin{array}{l}\text { Mean depth to } \\
\text { ice (m) }\end{array}$ & Range \\
\hline $46.35^{\circ}$ & $176.89^{\circ}$ & 6 & 0.42 & $0.28-0.58$ \\
\hline $44.22^{\circ}$ & $164.20^{\circ}$ & 5 & 0.47 & $0.26-0.55$ \\
\hline $50.51^{\circ}$ & $265.2^{\circ}$ & 3 & 0.42 & $0.32-0.62$ \\
\hline $39.11^{\circ}$ & $190.25^{\circ}$ & 2 & 0.90 & $0.69-1.1$ \\
\hline $47.43^{\circ}$ & $112.01^{\circ}$ & 2 & 0.50 & $0.40-0.60$ \\
\hline
\end{tabular}

1458 Planetocentric latitude, east longitude. $\mathrm{N}$ is the number of craters with morphologies

1459 indicating weak-over-strong layering, which are not necessarily those with visible ice.

1460 Values are given to two significant figures for relative comparison but for typical crater

1461 sizes, the potential measurement error on an individual crater is $\pm \sim 30 \%$ assuming half-

1462 pixel errors in opposite directions for the rim and floor diameter. The range is the spread

1463 between the largest and smallest measurements and does not include measurement

1464 uncertainty.

1465

1466 Figures and Captions 

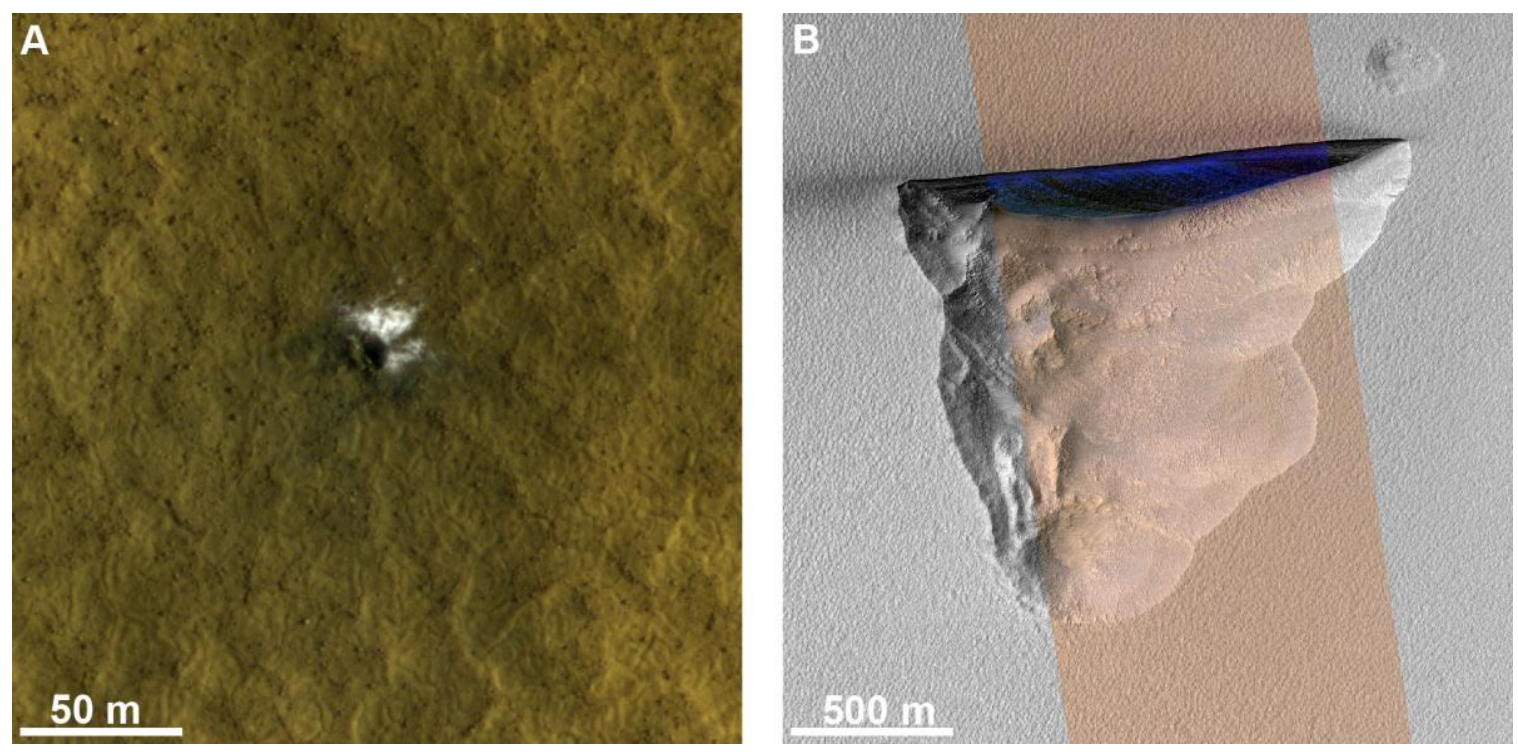

1468 Figure 1. A) Example of an ice-exposing crater $\left(69.3^{\circ} \mathrm{N}, 142.2^{\circ} \mathrm{E}\right)$. Note patchy, bright,

1469 relatively white ejecta, suggesting that this crater excavated both regolith and clean ice,

1470 as well as polygonal patterns consistent with thermal contraction cracks. B) Southern

1471 hemisphere ice-exposing scarp \#6 (56.9 $\left.{ }^{\circ} \mathrm{S}, 96.3^{\circ} \mathrm{E}\right)$. Note distinct relatively blue

1472 coloration confined to the scarp face, which is approximately straight, sharp-edged, and

1473 faces the pole. (A: HiRISE image ESP_046189_2495, acquired at $\mathrm{L}_{s}=163^{\circ}$. Illumination

1474 is from the right and north is to the lower left (polar stereographic projection). B: HiRISE

1475 image ESP_057466_1230, acquired at $\mathrm{L}_{S}=279^{\circ}$. Illumination is from the upper left and

1476 north is up. All image figures herein are map projected in equirectangular projection with

1477 north up unless otherwise noted, and colors are enhanced as described in the text.) 

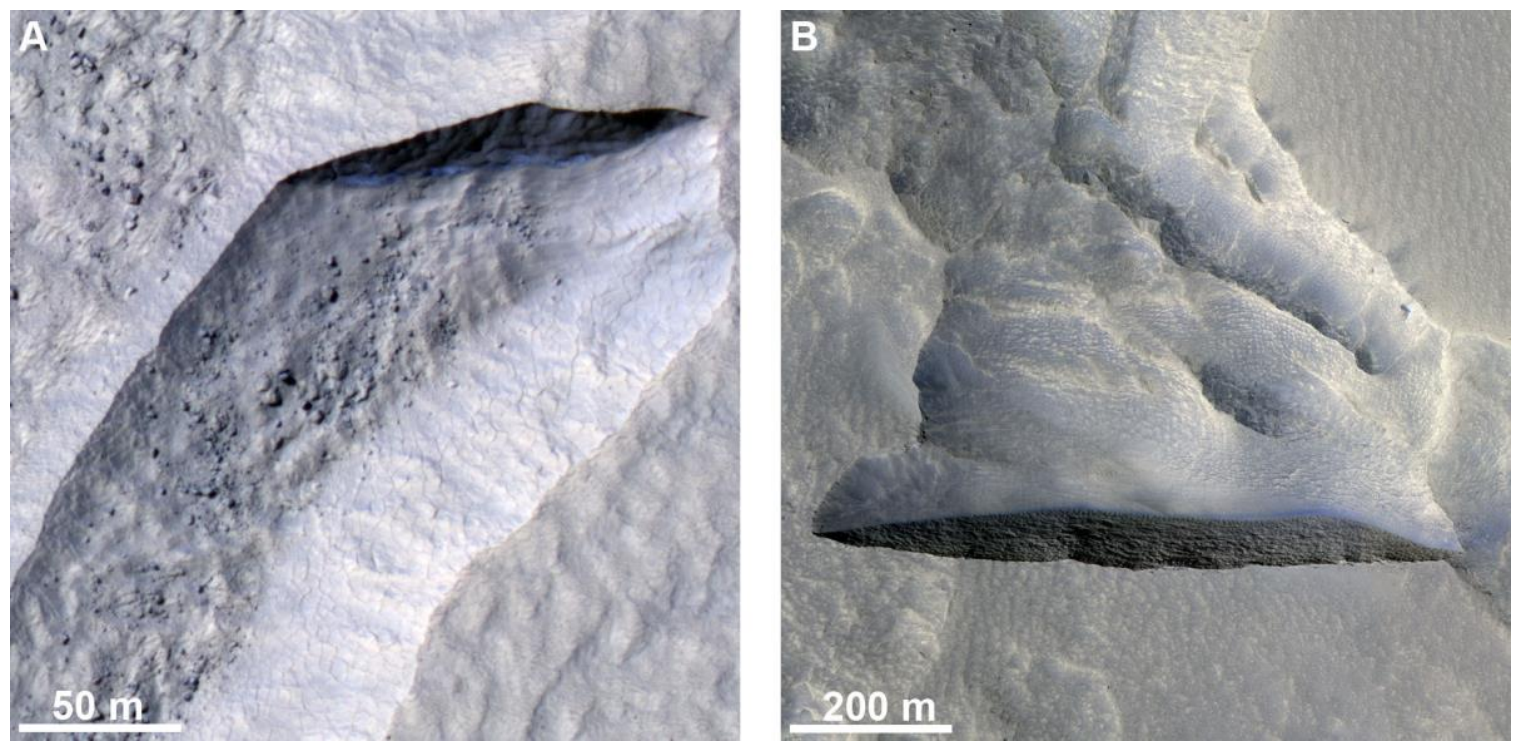

1479 Figure 2. A) Example of a confirmed but marginal icy scarp (southern hemisphere scarp

$1480 \# 13)$, where there is weak coloration of relatively blue material confined to only portions

1481 of the scarp face. B) Example of a scarp that has the morphology of an ice exposure but

1482 lacks the coloration. These are interpreted to represent the results of the same geomorphic

1483 processes that create distinctively colored scarps, but with coloration suppressed by a thin

1484 lag or somewhat higher lithic content. (A: HiRISE image ESP_057901_1235 (56.2 ${ }^{\circ} \mathrm{S}$,

$\left.1485103.1^{\circ} \mathrm{E}\right)$, acquired at $\mathrm{L}_{\mathrm{S}}=299^{\circ}$. B: HiRISE image ESP_052529_2345 (54.1 ${ }^{\circ} \mathrm{N}, 212.1$

$1486{ }^{\circ} \mathrm{E}$ ), acquired at $\mathrm{L}_{S}=72^{\circ}$. Illumination is from the upper (A) and lower (B) left.) 


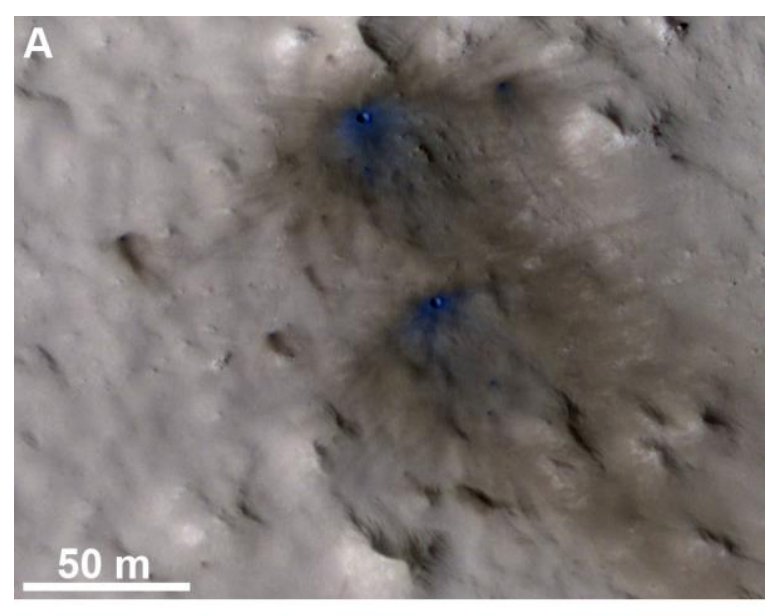

\section{B}

1488 Figure 3. Examples of new craters with distinctive ejecta that are not interpreted as ice

1489 indicators. A) Cluster of craters with relatively blue ejecta that is not notably bright or

1490 distinctive; this coloration is consistent with mafic material exposed by the impact. B)

1491 Crater with relatively bright ejecta. This material appears relatively yellow (bright in the

1492 HiRISE red filter) rather than blue or white, and all excavated material appears bright

1493 even though any ice present at this latitude should lie beneath a debris cover. In neither

1494 case is nearby geomorphology suggestive of ice-rich material, and these latitudes do not

1495 theoretically favor shallow stable ice. (A: HiRISE image ESP_055383_2135 (33.2 ${ }^{\circ} \mathrm{N}$,

$\left.149658.1^{\circ} \mathrm{E}\right)$, acquired at $\mathrm{L}_{S}=179^{\circ}$. B: HiRISE image ESP_044875_1650 $\left(14.7^{\circ} \mathrm{S}, 30.9^{\circ} \mathrm{E}\right)$,

1497 acquired at $\mathrm{L}_{S}=112^{\circ}$. Illumination is from the lower (A) and upper (B) left.) 


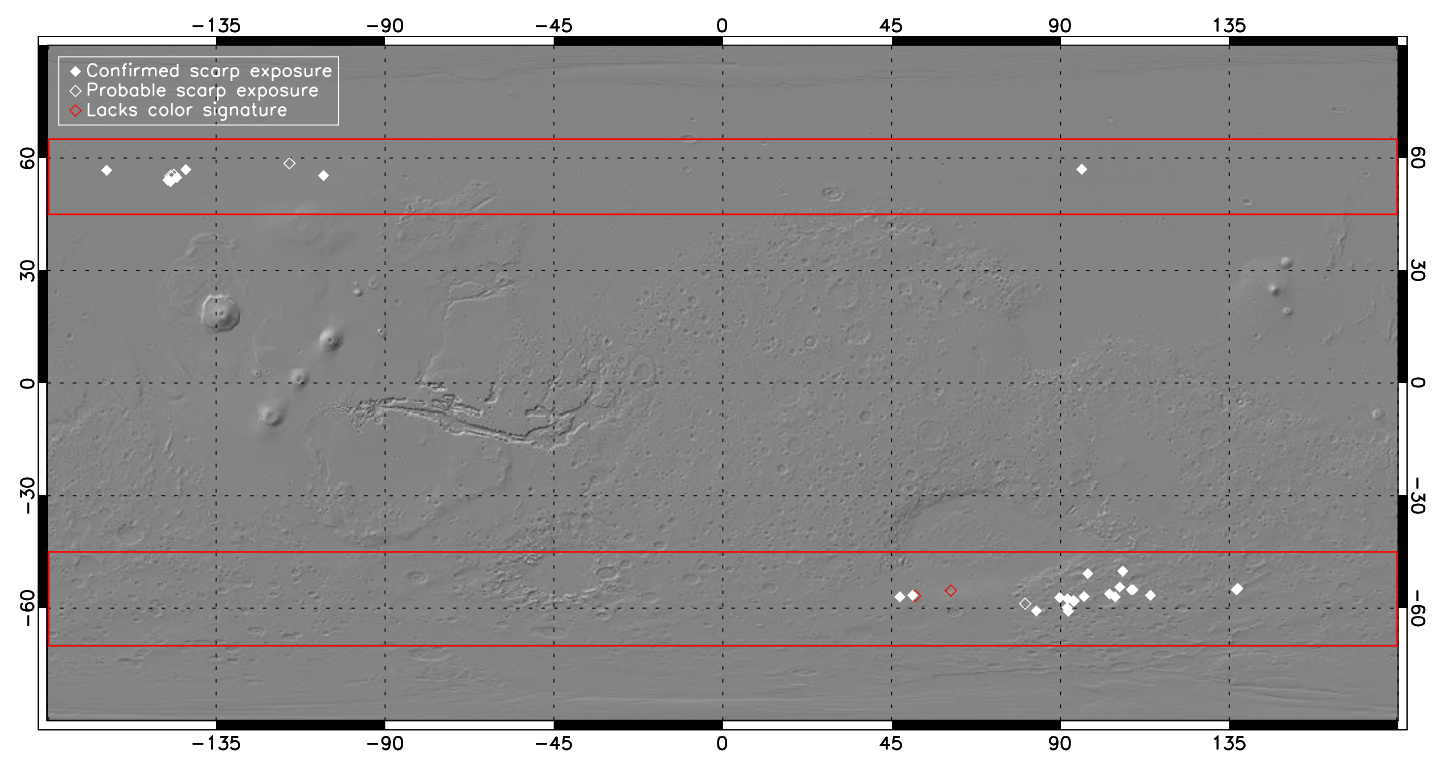

1499 Figure 4. Map of ice-exposing scarp locations identified between $45-70{ }^{\circ} \mathrm{S}$ and $45-65$

$1500{ }^{\circ} \mathrm{N}$. Confirmed scarps (relatively blue in HiRISE) are shown as solid symbols and

1501 probable scarps are open. Some symbols overlap. Red boxes outline the survey areas.

1502 Base map is shaded relief derived from the Mars Orbiter Laser Altimeter (MOLA) digital

1503 elevation model in simple cylindrical projection.

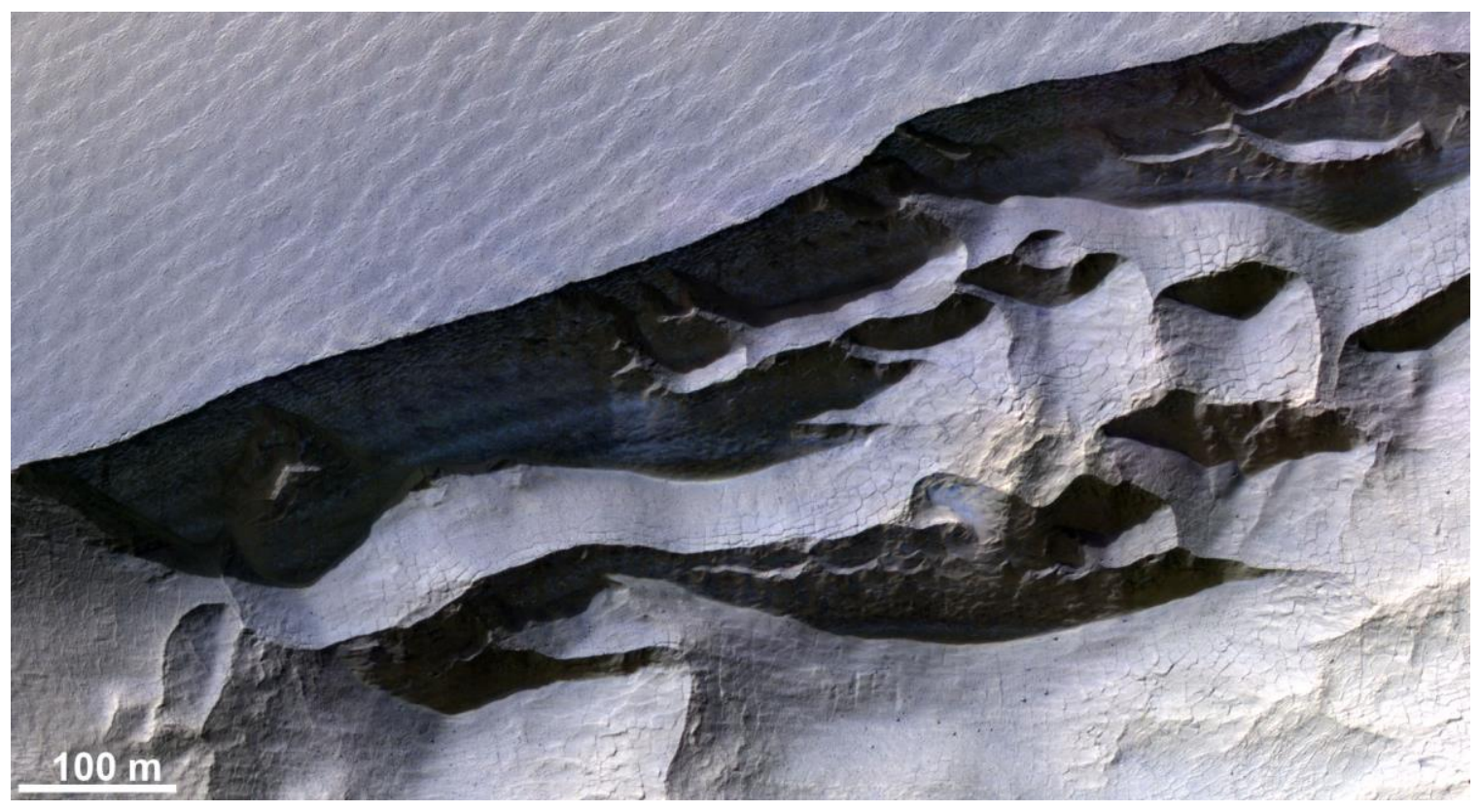


1505 Figure 5. Southern-hemisphere scarp \#15 (56.6 $\left.{ }^{\circ} \mathrm{S}, 50.6^{\circ} \mathrm{E}\right)$ has a complex structure. The 1506 primary scarp face and best ice exposure is largely in shadow. However, small parallel 1507 facets exist within the material at the base of the scarp. This demonstrates a high ice

1508 content within the residual material (the scarp did not erode to the base of the ice) and

1509 complex dynamics of reactivation. (HiRISE image ESP_058971_1230, acquired at

$1510 \mathrm{~L}_{S}=346^{\circ}$. Illumination is from the upper left.)

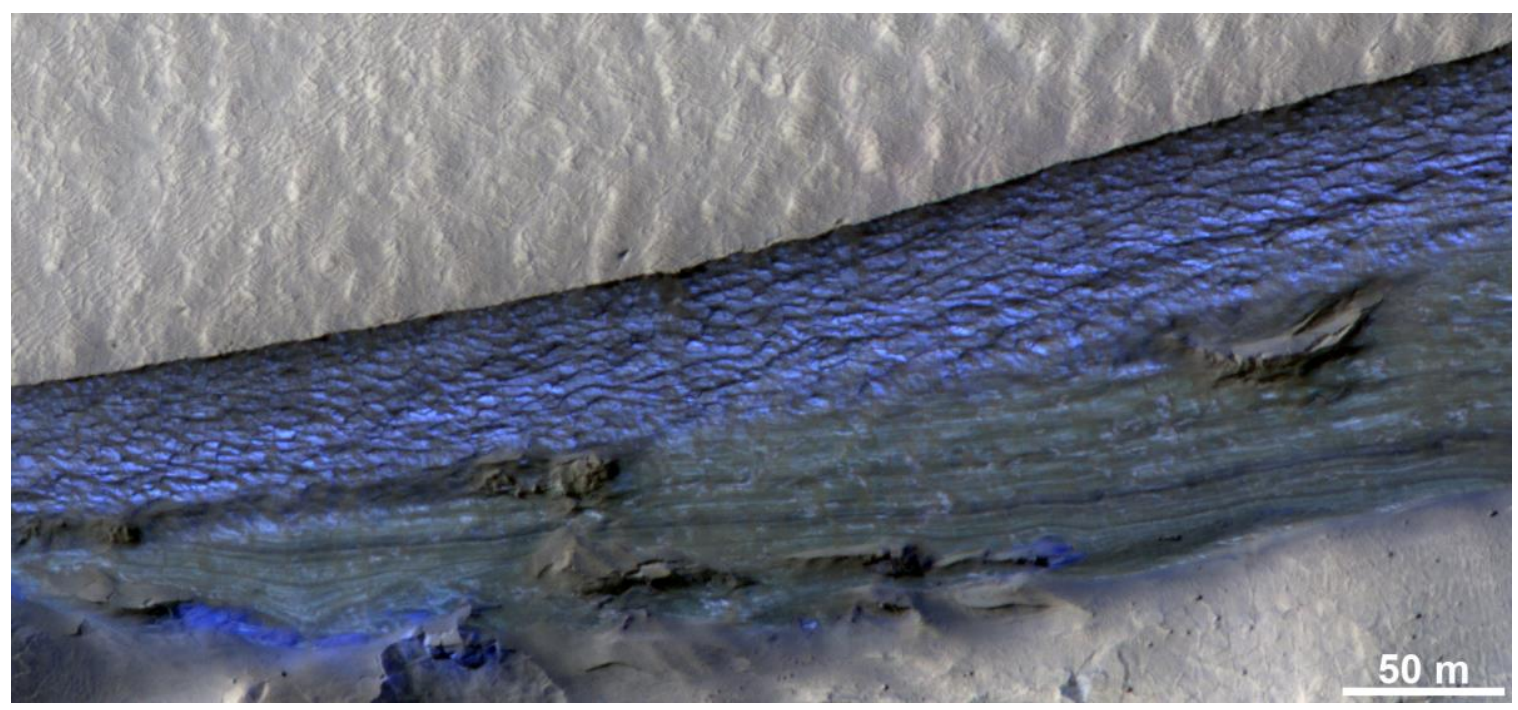

1512 Figure 6. Contrasting layering styles in southern-hemisphere scarp \#7 (57.5 $\left.{ }^{\circ} \mathrm{S}, 91.9^{\circ} \mathrm{E}\right)$.

1513 The lower slope (bottom of the image) shows a rare example of fine layering. The upper

1514 slope has a blocky and fractured appearance with some hints of horizontal banding,

1515 which is the typical appearance of most scarps. (HiRISE image ESP_057321_1220,

1516 acquired at $\mathrm{L}_{\mathrm{S}}=272^{\circ}$. Illumination is from the upper left.) 

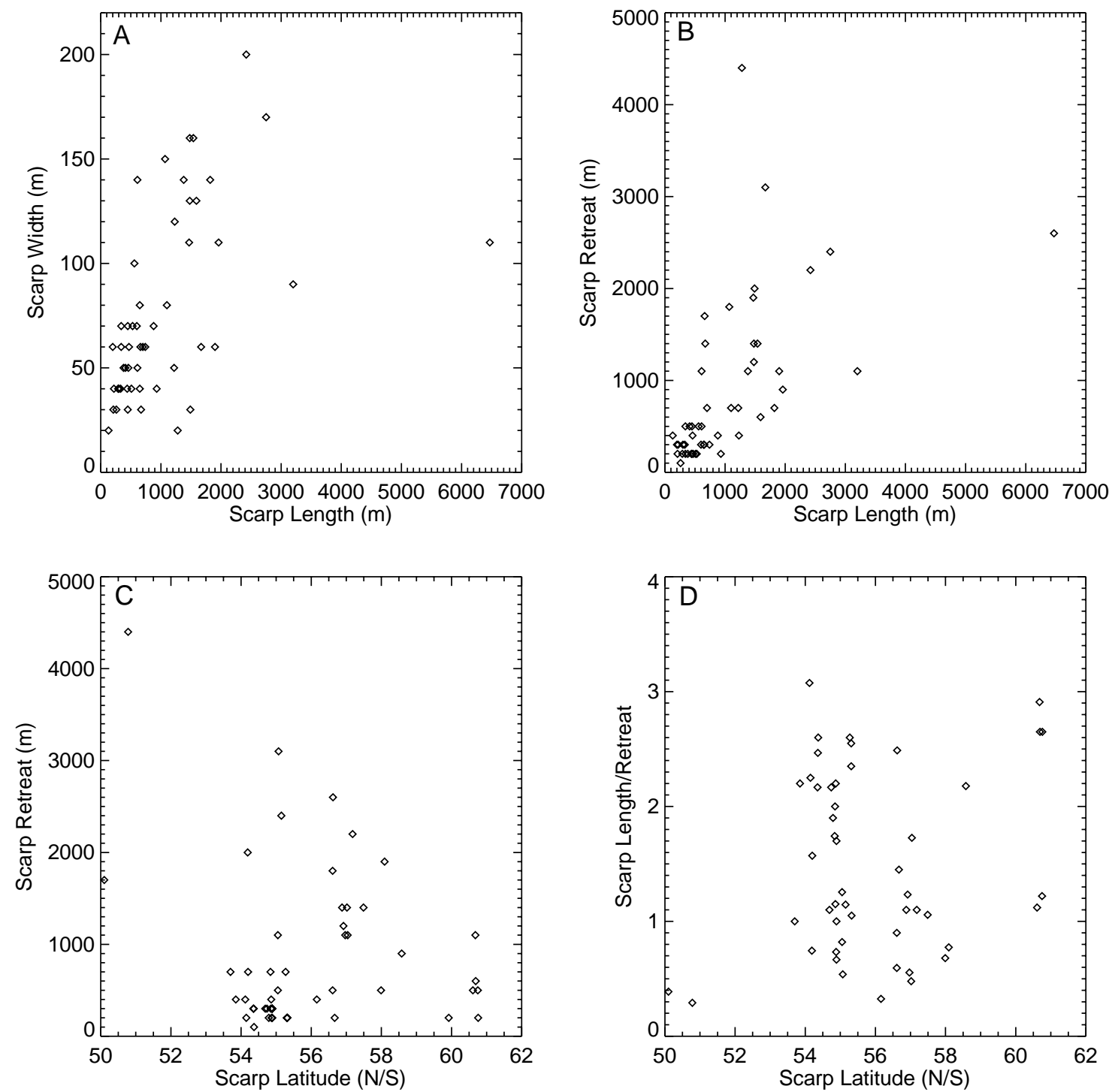

1517

1518 Figure 7. Quantitative morphometry of ice-exposing scarps. A) Scarp plan-view width

1519 (crest to base) versus end-to-end length. B) Scarp retreat distance versus end-to-end

1520 length. Both A and B show that wider scarps are generally taller and have retreated

1521 further. C) Scarp retreat distance versus latitude. The upper envelope of retreat distance

1522 decreases with increasing latitude. D) Pit aspect ratio (scarp length divided by retreat

1523 distance) versus latitude. All plots include data for confirmed scarps in both hemispheres. 


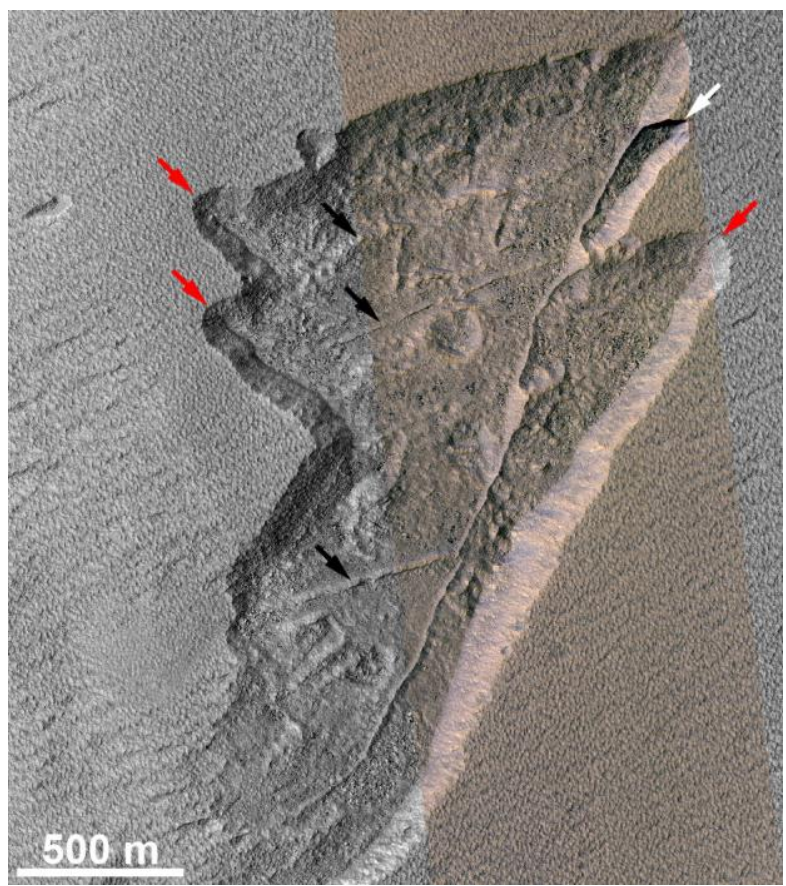

1525 Figure 8. The pit containing southern-hemisphere scarp \#13 (white arrow; see Fig. 2a for

1526 detail) reveals details of the scarp retreat process. Based on crosscutting relationships and

1527 the typical scarp geometry, the scarp initiated in the lower left part of the image and

1528 retreated approximately equatorward. It maintained the same approximate orientation

1529 throughout, as shown by several scarp-parallel ridges (black arrows). However, retreat

1530 may have been oblique rather than scarp-normal at times, since the scarp walls in the

1531 southern part of the pit are parallel but are not normal to the scarp. Multiple notches in

1532 the pit walls (red arrows) demonstrate that the scarp width varied over time and that the

1533 outer parts sometimes became inactive. It is possible that the entire scarp deactivated and

1534 only the central sections subsequently resumed retreating. Finally, secondary scarps such

1535 as the current scarp reactivated on the east side of the pit, producing a younger ridge that

1536 defines the old edge of the pit. (HiRISE image ESP_057901_1235 (56.2 $\left.{ }^{\circ} \mathrm{S}, 103.1{ }^{\circ} \mathrm{E}\right)$,

1537 acquired at $\mathrm{L}_{S}=299^{\circ}$. Illumination is from the upper left.) 

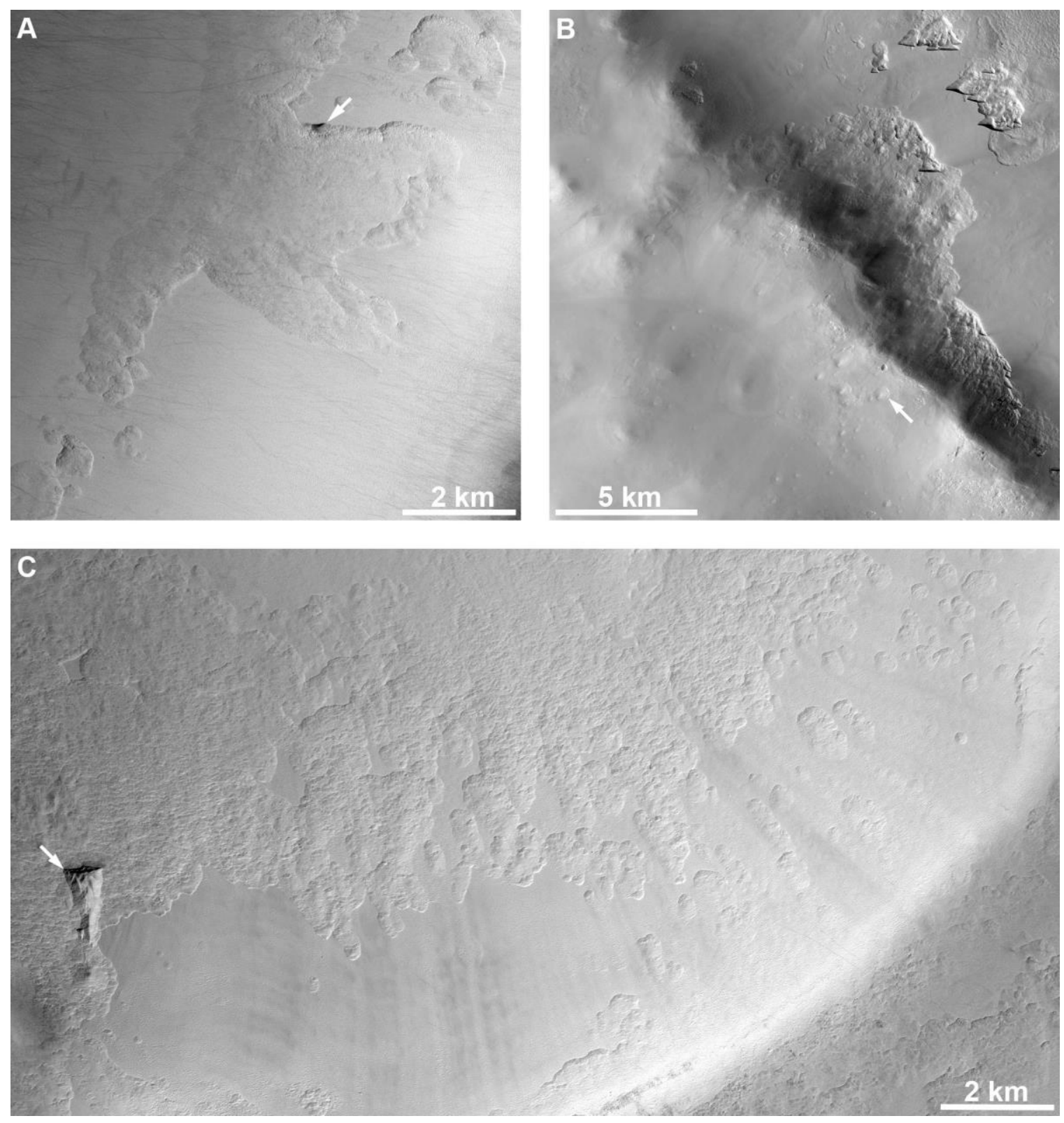

1539 Figure 9. Scalloped depressions and ice-loss landforms. A) Probable ice-exposing

1540 southern-hemisphere scarp \#18 (arrow; $58.8^{\circ} \mathrm{S}, 80.6^{\circ} \mathrm{E}$ ) eroding into a mantling unit that

1541 is also being removed to form scalloped depressions. The scarp resembles parts of the

1542 scalloped depressions but is the most-shadowed (steepest) slope in the area. B) A group

1543 of scarps in southwestern Milankovič crater $\left(54^{\circ} \mathrm{N}, 212^{\circ} \mathrm{E}\right)$ with expanded craters

1544 nearby (arrow indicates a prominent example). Although both occur in mantling 
1545 materials, the scarps are concentrated inside the crater rim and the craters beyond it. C)

1546 Southern-hemisphere ice-exposing scarp \#14 (arrow) occurs in the vicinity of classic

1547 scalloped depressions prominent in the eastern part of the image $\left(57^{\circ} \mathrm{S}, 47.2^{\circ} \mathrm{E}\right)$. The

1548 well-defined scallops are within a pristine mantling unit while the scarp is cut into

1549 partially degraded material that may have been previously dissected by scallop formation.

1550 Note that the triangular scarp-pit morphology is distinct from the scalloped depressions in

1551 shape and scale. (A: CTX image B10_013661_1211_XN_58S279W. Illumination is from

1552 the upper left. B: CTX image J22_053320_2345_XN_54N148W. Illumination from the

1553 lower left. C: CTX image K11_057692_1221_XN_57S312W. Illumination is from the

1554 upper left.)

1555

1556

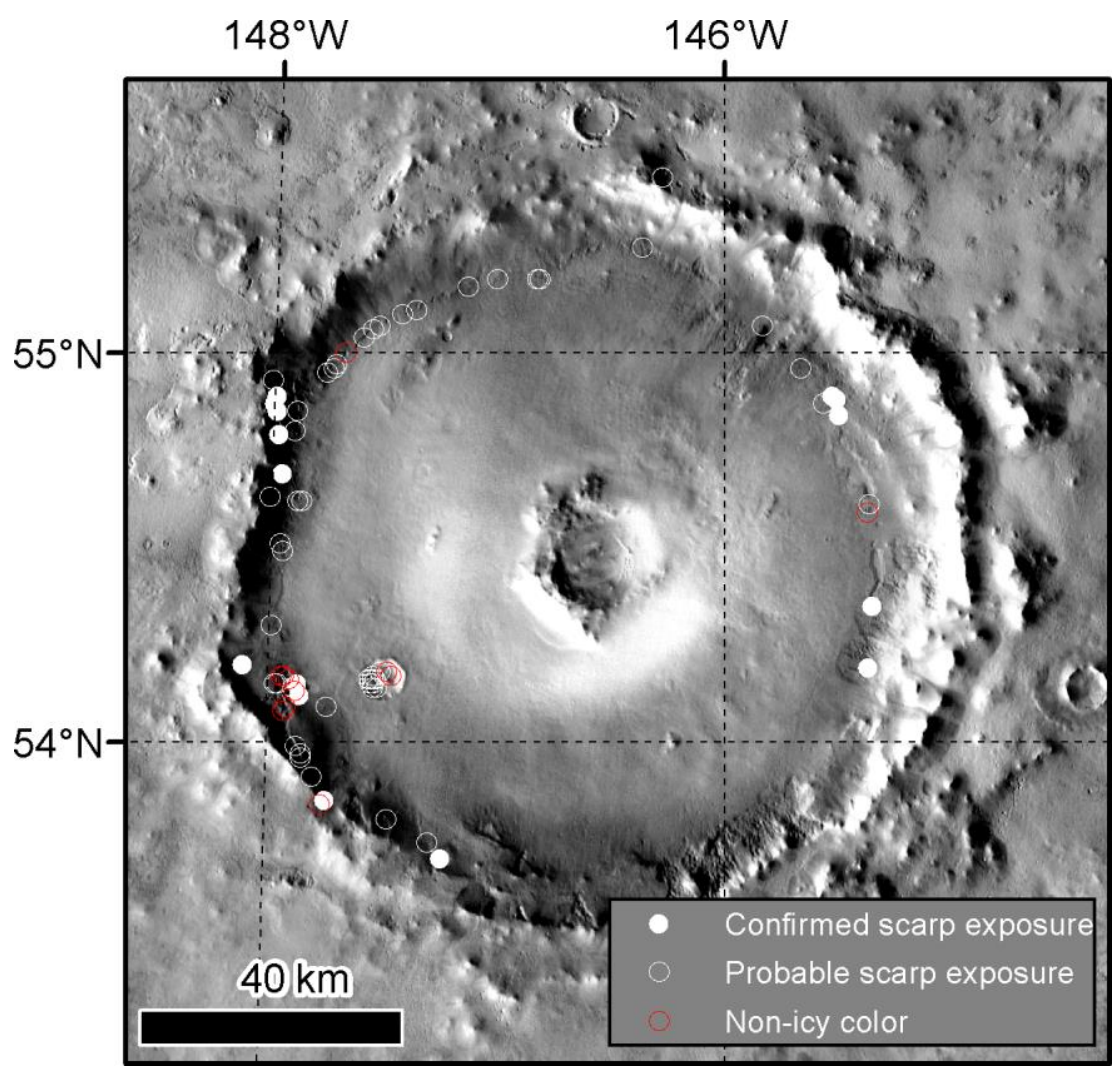


1557 Figure 10. Map of scarps in Milankovič crater. Solid white circles show confirmed icy

1558 scarps, open white circles are classified as probable, and red symbols have the

1559 morphology of icy scarps but lack the coloration in HiRISE images. Scarps generally line

1560 the base of the crater rim, apart from a cluster in a smaller crater within Milankovič. Base

1561 map is the THEMIS controlled mosaic in sinusoidal projection centered on $146^{\circ} \mathrm{W}$.
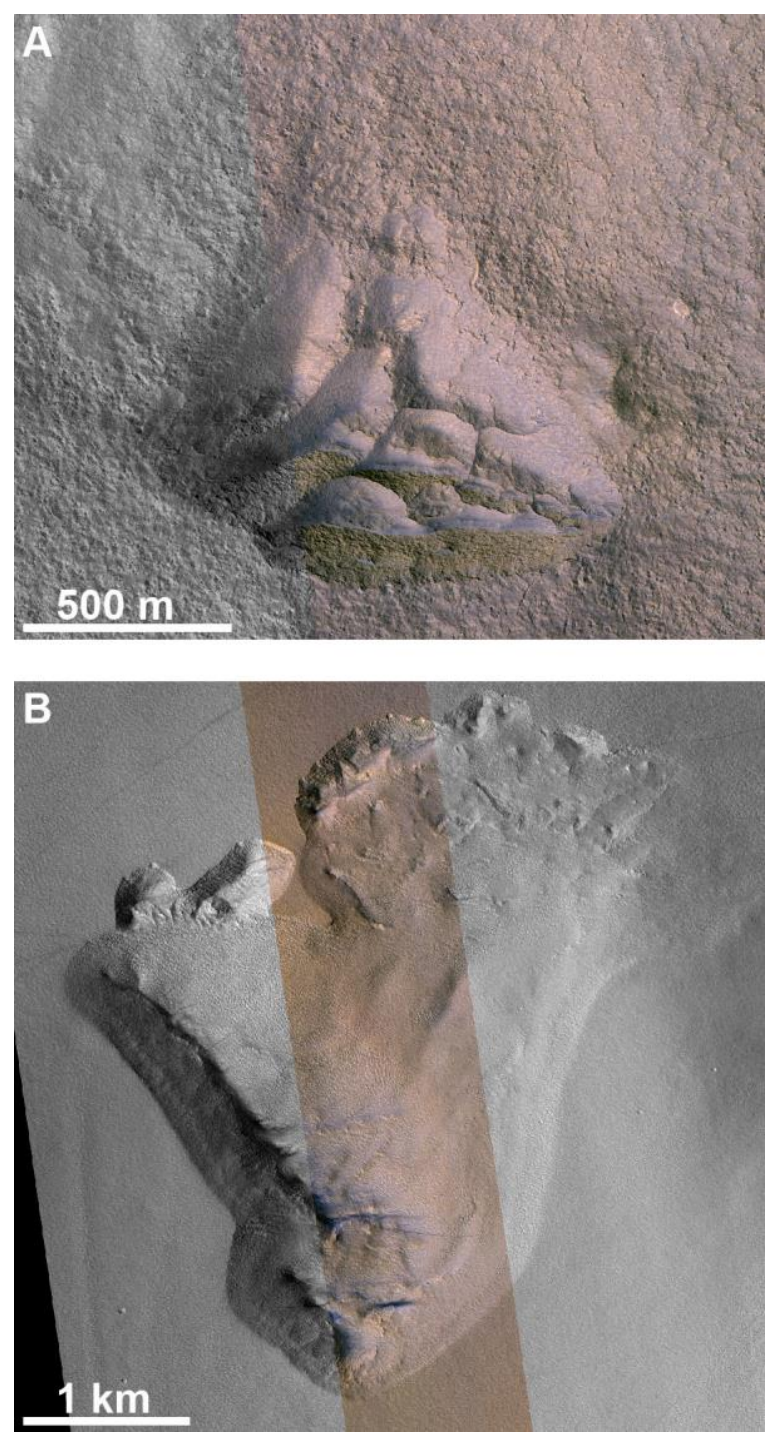

1563 Figure 11. Pits with morphologies similar to ice-exposing scarp locations, but without

1564 well-defined scarps or distinct relatively blue exposures. (A: HiRISE image

1565 ESP_061998_2405 $\left(60.4^{\circ} \mathrm{N}, 197.8^{\circ} \mathrm{E}\right)$, acquired at $\mathrm{L}_{S}=95^{\circ}$. B: HiRISE image 
1566 ESP_057176_1255 $\left(54^{\circ} \mathrm{S}, 90.2^{\circ} \mathrm{E}\right)$, acquired at $\mathrm{L}_{S}=265^{\circ}$. Illumination is from the left in 1567 both panels.)

1568

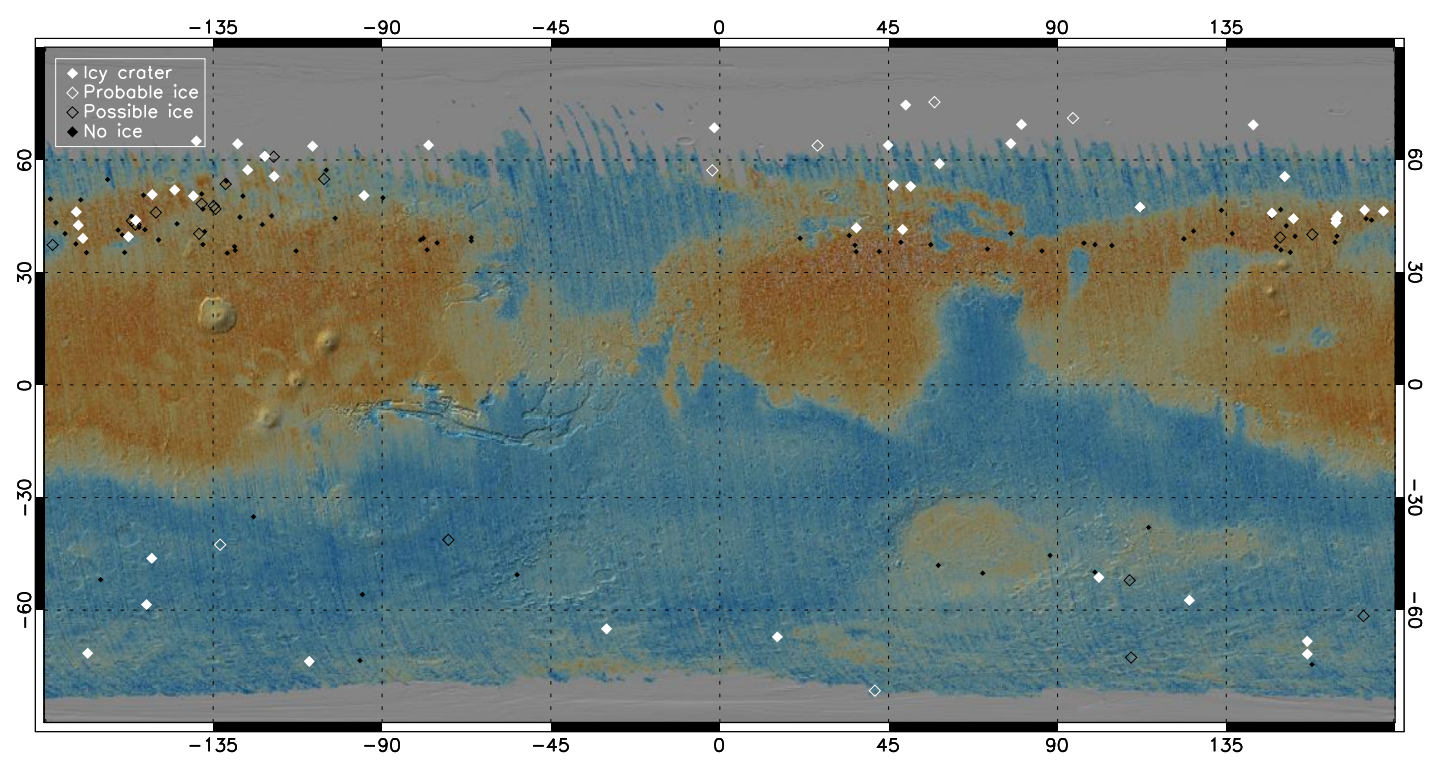

1569 Figure 12. Map of confirmed and probable ice-exposing craters (solid and open white

1570 diamonds respectively), possible ice-exposing craters (open black diamonds), and non-

1571 ice-exposing craters (black points) poleward of $35^{\circ}$ latitude in each hemisphere. New

1572 dated impacts equatorward of $35^{\circ} \mathrm{N} / \mathrm{S}$ are not shown in this figure. The background map

1573 is the dust-cover index map of Ruff and Christensen (2002) in simple cylindrical

1574 projection; new impact detections overall are biased towards dusty regions (orange and

1575 yellow tones) although bright ice exposure might aid crater detection in non-dusty

1576 regions. 

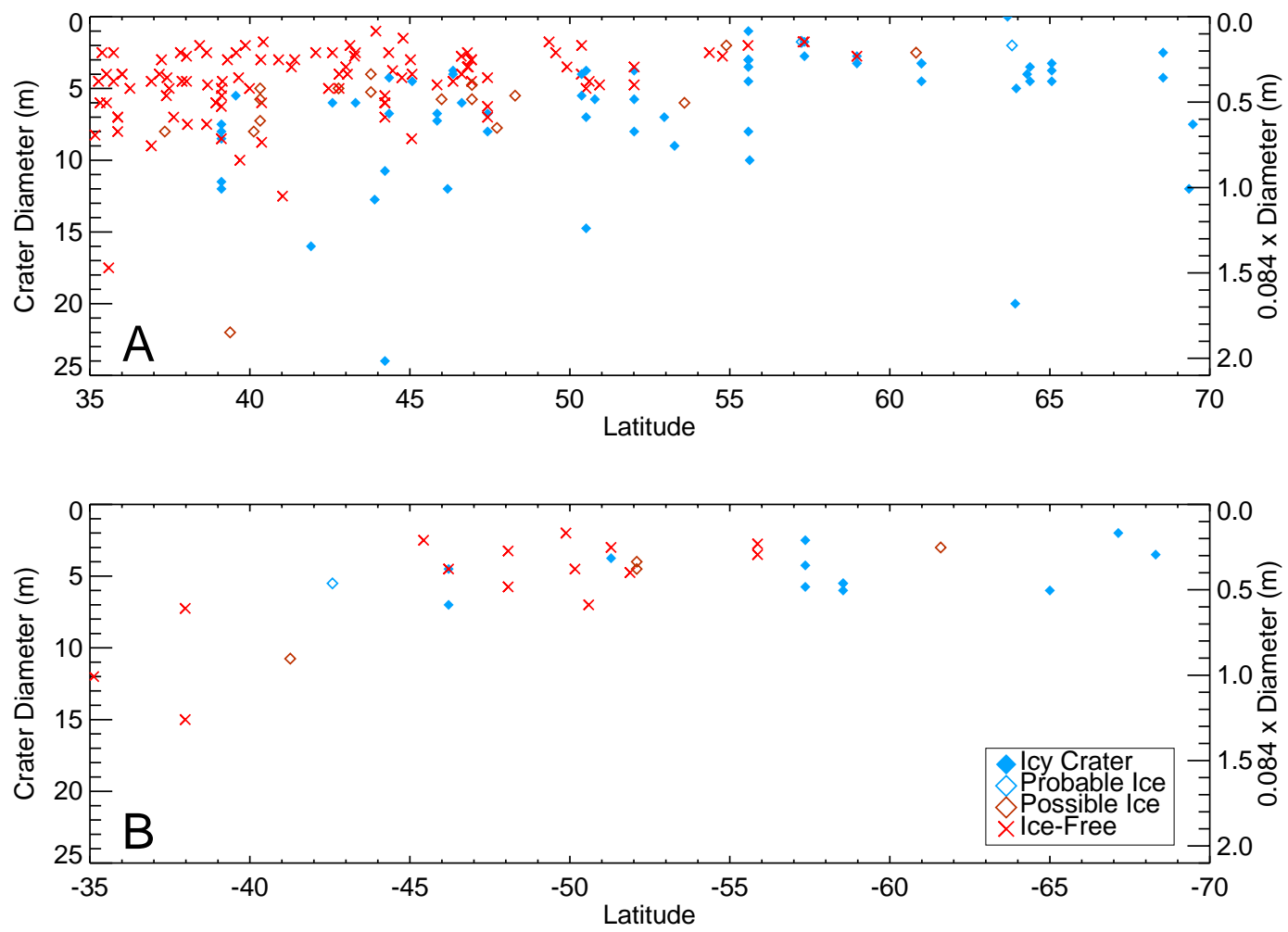

1577

1578 Figure 13. Plot of latitude vs. crater diameter for new impacts in the northern hemisphere

1579 (A) and southern hemisphere (B). Probable and confirmed ice-exposing craters are shown

1580 in blue. The right-hand axis shows $0.084 \times$ the crater diameter, an estimate of the

1581 maximum excavation depth. Some craters are at latitudes or diameters larger than the

1582 maximum plotted but are excluded to enhance visibility of the shallow craters and

1583 transitional latitudes. In both hemispheres the depth to ice becomes shallower at high

1584 latitude, but at latitudes where ice exists it is commonly present at a depth $<1 \mathrm{~m}$,

1585 consistent with ice stability theory. 

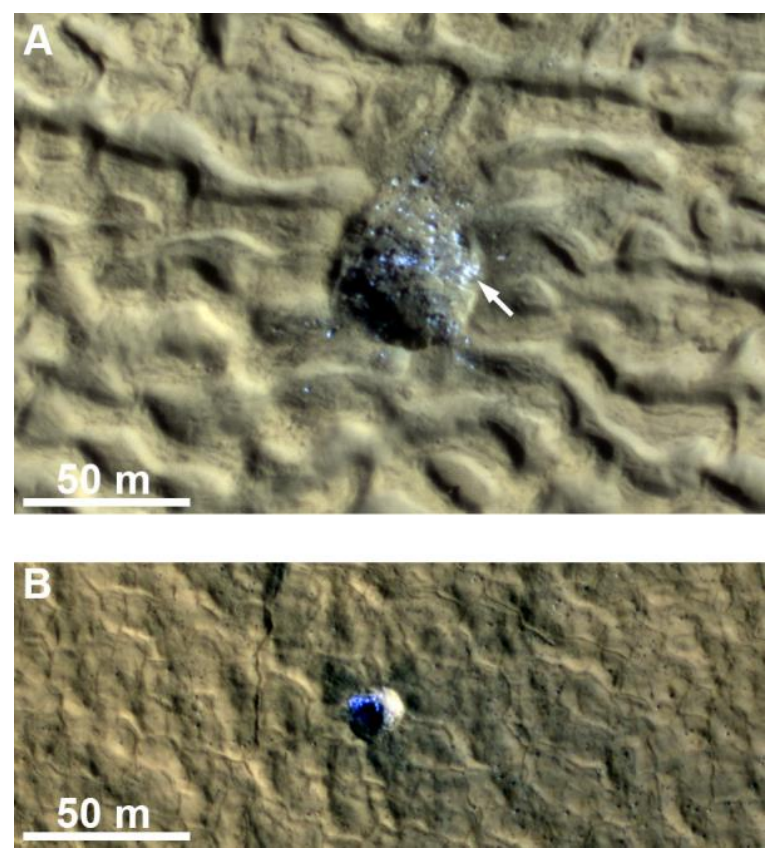

1587 Figure 14. Ice-exposing craters in the Protonilus Mensae region. Both craters excavate

1588 blocky ice-rich material. On the east (west-facing) crater wall, ice appears to be within

1589 the core of a ridge (arrow). (A: HiRISE image ESP_046707_2220 $\left(41.4^{\circ} \mathrm{N}, 48.8^{\circ} \mathrm{E}\right)$,

1590 acquired at $\mathrm{Ls}_{\mathrm{S}}=185^{\circ}$. B: HiRISE image ESP_046747_2220 (41.9 $\left.{ }^{\circ} \mathrm{N}, 36.4^{\circ} \mathrm{E}\right)$, acquired

1591 at $\mathrm{L}_{\mathrm{S}}=187^{\circ}$. Illumination is from the lower left in both panels.)
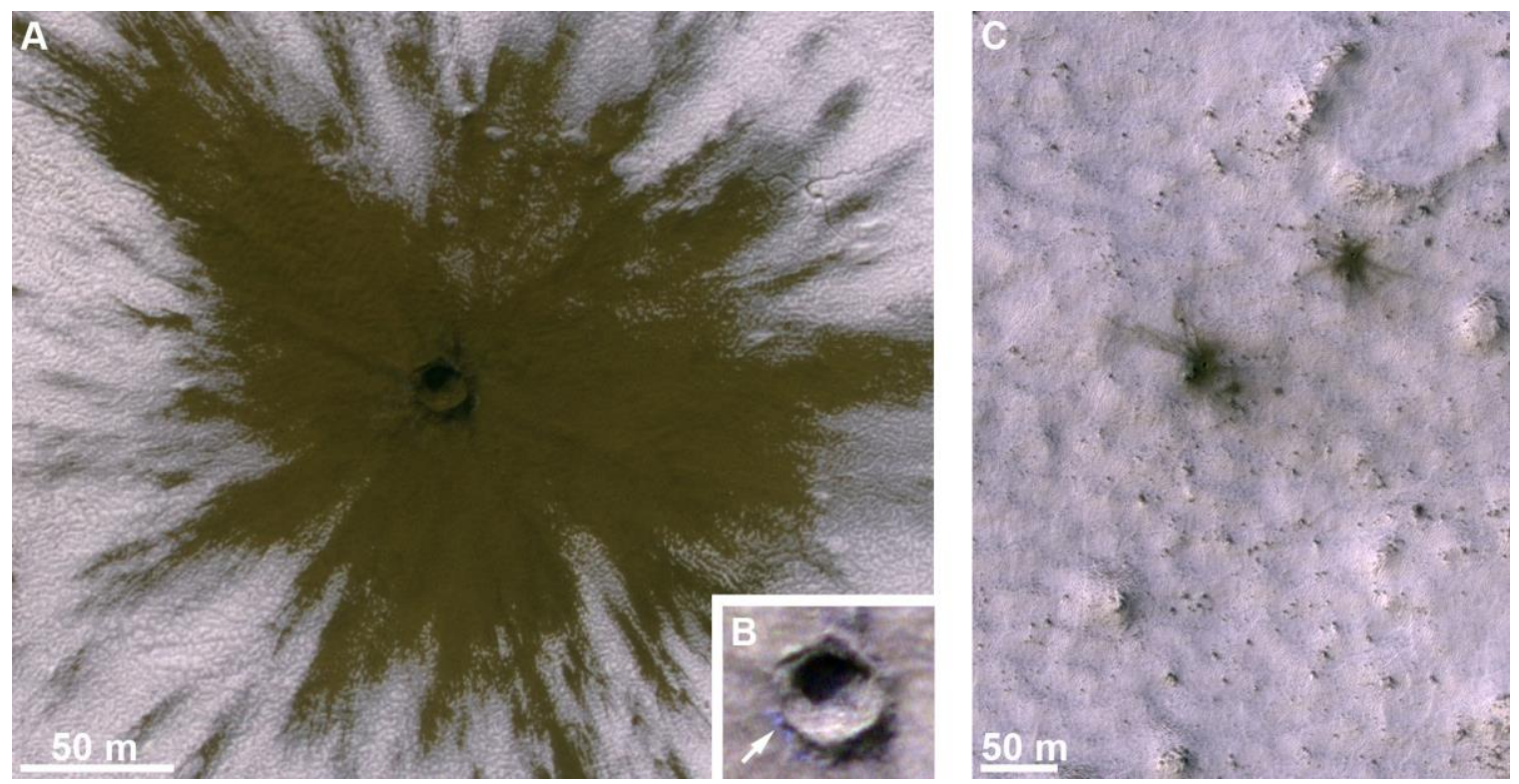
1593 Figure 15. New impact craters with ejecta superposing seasonal frost. A) Crater on the 1594 south polar layered deposits $\left(81.5^{\circ} \mathrm{S}, 41.4^{\circ} \mathrm{E}\right)$. B) The same crater $(2 \times$ enlarged $)$ after

1595 defrosting. Arrow indicates a minor exposure of relatively-blue material interpreted as 1596 probable ground ice; however, despite the ice-rich nature of the SPLD and substantial

1597 size of this crater, the distinct ice deposit is minimal even though images were acquired

1598 rapidly after formation. Note that the color stretch in this cutout is different from that in

1599 A, to emphasize relative color variations; the crater and immediate surroundings are

1600 unchanged but there is no longer frost providing a strong relative contrast. C) Small

1601 craters with ejecta superposing the seasonal $\mathrm{CO}_{2}$ cap $\left(55.9^{\circ} \mathrm{S}, 264.8^{\circ} \mathrm{E}\right) .(\mathrm{A}: \mathrm{HiRISE}$

1602 image ESP_057152_0985 $\left(\mathrm{L}_{S}=263^{\circ}\right)$. North is towards upper right (polar stereographic

1603 projection) and illumination from the top. B: HiRISE image ESP_057574_0985

$1604\left(\mathrm{~L}_{S}=284^{\circ}\right) . \mathrm{C}$ : HiRISE image ESP_037284_1240 $\left(\mathrm{L}_{S}=159^{\circ}\right)$. North is up and illumination

1605 from the upper left.)
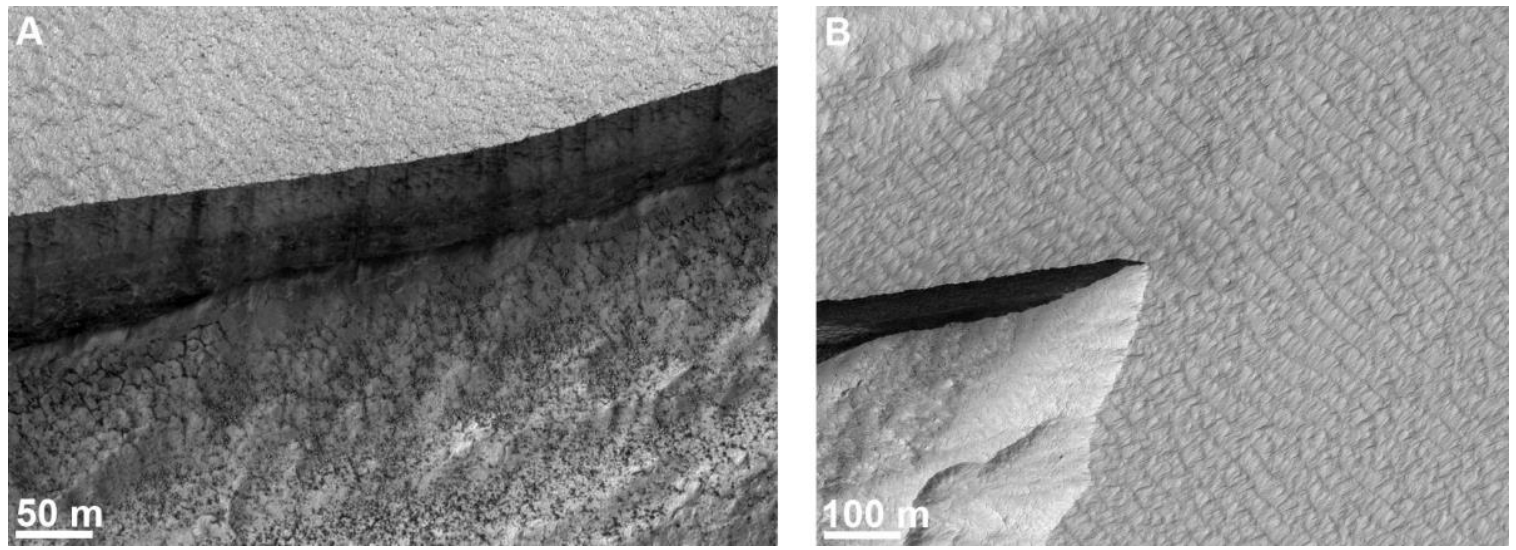

1607 Figure 16. Possible modification processes maintaining ice exposures. A) Striations on

1608 the surface of a scarp with likely winter frost cover suggest active frost-driven mass

1609 wasting. B) Ridges on the plateau surface above southern-hemisphere scarp \#3 resemble

1610 bedforms interpreted as dust accumulation features by Geissler (2014) and indicate winds 
1611 from the upper right. (A: HiRISE image ESP_064006_1245 (55.1 $\left.{ }^{\circ} \mathrm{S}, 109.4{ }^{\circ} \mathrm{E}\right)$, acquired 1612 at $\mathrm{L}_{S}=171^{\circ}$. B: HiRISE image ESP_040772_1215 (58.1 $\left.{ }^{\circ} \mathrm{S}, 93.7^{\circ} \mathrm{E}\right)$, acquired at $1613 \mathrm{~L}_{S}=322^{\circ}$. Illumination is from the upper left in both panels.)

1614 